IZA DP No. 8633

Does Marriage Make You Healthier?

Nezih Guner

Yuliya Kulikova

Joan Llull

November 2014

Forschungsinstitut

zur Zukunft der Arbeit

Institute for the Study

of Labor 


\title{
Does Marriage Make You Healthier?
}

\author{
Nezih Guner \\ ICREA-MOVE, Universitat Autònoma de Barcelona, \\ Barcelona GSE and IZA \\ Yuliya Kulikova \\ Universitat Autònoma de Barcelona \\ and Barcelona GSE \\ Joan Llull \\ MOVE, Universitat Autònoma de Barcelona \\ and Barcelona GSE

\section{Discussion Paper No. 8633 \\ November 2014} \\ IZA \\ P.O. Box 7240 \\ 53072 Bonn \\ Germany \\ Phone: $+49-228-3894-0$ \\ Fax: +49-228-3894-180 \\ E-mail: iza@iza.org
}

Any opinions expressed here are those of the author(s) and not those of IZA. Research published in this series may include views on policy, but the institute itself takes no institutional policy positions. The IZA research network is committed to the IZA Guiding Principles of Research Integrity.

The Institute for the Study of Labor (IZA) in Bonn is a local and virtual international research center and a place of communication between science, politics and business. IZA is an independent nonprofit organization supported by Deutsche Post Foundation. The center is associated with the University of Bonn and offers a stimulating research environment through its international network, workshops and conferences, data service, project support, research visits and doctoral program. IZA engages in (i) original and internationally competitive research in all fields of labor economics, (ii) development of policy concepts, and (iii) dissemination of research results and concepts to the interested public.

IZA Discussion Papers often represent preliminary work and are circulated to encourage discussion. Citation of such a paper should account for its provisional character. A revised version may be available directly from the author. 
IZA Discussion Paper No. 8633

November 2014

\section{ABSTRACT}

\section{Does Marriage Make You Healthier?*}

We use the Panel Study of Income Dynamics (PSID) and the Medical Expenditure Panel Survey (MEPS) to study the relationship between marriage and health for working-age (20 to 64) individuals. In both data sets married agents are healthier than unmarried ones, and the health gap between married and unmarried agents widens by age. After controlling for observables, a gap of about 12 percentage points in self-reported health persists for ages 5559. We estimate the marriage health gap non-parametrically as a function of age. If we allow for unobserved heterogeneity in innate permanent health, potentially correlated with timing and likelihood of marriage, we find that the effect of marriage on health disappears at younger (20-39) ages, while about 6 percentage points difference between married and unmarried individuals, about half of the total gap, remains at older (55-59) ages. These results indicate that association between marriage and health is mainly driven by selection into marriage at younger ages, while there might be a protective effect of marriage at older ages. We analyze how selection and protective effects of marriage show up in the data.

JEL Classification: $\quad 110, \mathrm{I} 12, \mathrm{~J} 10$

Keywords: health, marriage, selection

Corresponding author:

Nezih Guner

MOVE (Markets, Organizations and Votes in Economics)

Facultat d'Economia, Universitat Autònoma de Barcelona

Edifici B - Campus de Bellaterra

08193 Bellaterra

Cerdanyola del Vallès (Spain)

E-mail: nezih.guner@movebarcelona.eu

\footnotetext{
* We would like to thank Matt Delventhal, Giacomo De Giorgi, Francesco Fasani, Ada Ferrer-iCarbonell, and workshop and conference participants at the European Meeting of the Econometric Society in Toulouse, the Annual Meetings of the Spanish Economic Association in Santander, Barcelona GSE Winter Workshop, CINCH Summer Academy at the University of Duisburg-Essen, Koç University (Istanbul), Universitat Autònoma de Barcelona for comments. Guner and Llull acknowledge financial support from European Research Council (ERC) through Starting Grant n.263600, and from the Spanish Ministry of Economy and Competitiveness, through the Severo Ochoa Programme for Centers of Excellence in R\&D (SEV-2011-0075).
} 


\section{Introduction}

Married individuals are healthier and live longer than unmarried ones. This fact was first documented by British epidemiologist William Farr more than 150 years ago, and has been established by many studies since then. ${ }^{1}$ The question is, of course, why? Does the association between marriage and health indicate a causal effect of marriage on health (what is termed in the literature as the protective effect of marriage), or is it simply an artifact of selection as healthier people are more likely to get married in the first place? ${ }^{2}$ The answer to this question is critical as it has important implications for public policy. ${ }^{3}$ Recent studies on the link between public policy and health suggest that "upstream social and economic determinants of health are of major health importance, and hence that social and economic policy and practice may be the major route to improving population health." (House, Schoeni, Kaplan and Pollack, 2008, p.22). Marriage is often portrayed as a solution for many social problems in the U.S., see e.g. Waite and Gallagher (2000), and the effectiveness of pro-marriage policies depends on whether marriage indeed makes individuals healthy, wealthy and happy.

In this paper we study the relationship between health and marriage using data from the Panel Study of Income Dynamics (PSID) and the Medical Expenditure Panel Survey (MEPS). In both data sets married individuals report to be healthier than unmarried ones, and they do so in remarkably similar levels. The gap in selfreported health persists after we control for observable characteristics such as education, income, race, gender and the presence of children: the marriage health gap starts at about 3 percentage points at younger ages (20 to 39), and increases continuously for older ages, reaching a peak of 12 percentage points around ages 55 to 59. A similar picture emerges when we consider objective, instead of selfreported, measures of health, or when we use the occurrence of chronic conditions as an indicator of poor health.

Our definition of the marriage health gap is the difference between age-dependent health curves for married and single individuals. These health curves are identified non-parametrically. Different studies in evolutionary biology suggest that several physical and personality traits that define a person as attractive for mating are

\footnotetext{
1 On Farr's study, see Parker-Pope (2010).

2 A similar question arises for the well-known married male wage premium.

3 "Between 1950 and 2011, real GDP per capita grew at an average of 2.0\% per year, while real national health care expenditures per capita grew at $4.4 \%$ per year. The gap between the two rates of growth $-2.4 \%$ per year - resulted in the share of the GDP related to health care spending increasing from $4.4 \%$ in 1950 to $17.9 \%$ in 2011." (Fuchs, 2013, p.108).
} 
associated with youth and health, and, as a result, with reproductive capacity. ${ }^{4}$ As a result, individuals with better innate health tend to be more attractive in the marriage market. If individuals with better innate health are more attractive marriage partners, and, as a result, more likely to get married in the first place, least squares estimates will be upward biased.

Using the panel structure of the PSID, we overcome this selection bias by accounting for individual-specific innate permanent health, potentially correlated with the timing and likelihood of marriage. With a within-groups estimation, the effect of marriage on health disappears for younger (20-39) ages, while about a 6 percentage point gap between married and unmarried individuals remains for older (55-59) ages. This is half of the total difference for this age group (12 percentage points). These results suggest that association between marriage and health at younger ages is likely to be driven by selection of healthier individuals into marriage, while there might be a protective effect of marriage that shows up at older ages. We also find that the marriage health gap is similar for males and females, blacks and whites, and for individuals with and without a college degree. The marriage health gap is, however, larger for poorer individuals.

Next we investigate how selection and protection might show up in the data. First, we show that individuals who are ever married by age 30 (or 40) have better average innate permanent health than those individuals who are never married by that age. The variance of permanent health, on the other hand, is larger for those who are never married. These facts are consistent with a world in which individuals look for healthy partners in the marriage market. In such a world, individuals would mate assortatively in terms of innate permanent health, and innate health should be a good predictor of marriage probabilities. We find evidence supporting both predictions. The correlation between our recovered measure of innate permanent health of husbands and wives is about $40 \%$, and remains large and significant (about 33\%) even after controlling for college, race, and a measure of permanent income. Furthermore, among individuals who are never-married by age 25 , a one standard deviation in innate permanent health is associated with an increase in the probability of being married at some point between ages 30 and 40 of about 4 percentage points. After accounting for innate permanent health, however, past health is uncorrelated with marriage probabilities, and, if anything, the association is negative. This suggests that our estimates of the protective effect of marriage may be even conservative.

\footnotetext{
${ }^{4}$ For instance, see Buss (1994) and Dawkins (1989).
} 
We then turn our focus to positive effects of marriage on health that are not captured by selection. We first show that the effect of marriage on health is cumulative. At a given age, the total number of years that an individual lives as married, what we call marriage capital, has a positive and significant effect on health. Given the importance of marriage capital, we estimate the effect of marriage on health innovations, estimating a dynamic model for current health that controls for lagged health. The estimated effect of marriage on health is then even larger, about twice as large as the within-group estimates. This is consistent with our previous result that, after accounting for innate permanent health, past health is, if anything, negatively correlated with marriage prospects.

Our results also show that married individuals are more likely to engage in preventive medical care than singles are, even after controlling for observable characteristics (including health expenditures, health insurance, and socio-economic variables). Married individuals around ages 50 to 54, for example, are about $6 \%$ more likely to check their cholesterol or have a prostate or breast examination. Marriage also promotes healthy habits. We focus on smoking, a major health risk. Our results show that a single individual is about 13 percentage points more likely to quit smoking if he/she gets married than if he/she stays single. Furthermore, a majority (about $72 \%$ ) of singles who get married and quit do so while they are married. The importance of healthy behavior also shows up in health expenditure patterns. While married agents spend more on their health when they are young and healthy, singles end up spending more than married ones in later years when they are older and less healthy. A possible important factor behind these differences is health insurance: while about $10 \%$ of married individuals do not have any, public or private, insurance, $20 \%$ of unmarried females and $25 \%$ of unmarried males lack health insurance.

This paper is related to the large literature on the relation between socioeconomic status and health (Stowasser, Heiss, McFadden and Winter, 2012). It is well documented that marriage is associated with positive health outcomes. Wood, Avellar and Goesling (2009) and Wilson and Oswald (2005) provide reviews of existing evidence. There is also a large and positive effect of education on health (e.g. Lleras-Muney, 2005; Cutler and Lleras-Muney, 2010), which goes beyond the higher financial resources that it brings (Gardner and Oswald, 2004; Smith, 2007).

The existing literature on marriage and health mainly focuses on mortality as key physical health outcome. The effect of marital status on mortality is often studied by regressing mortality on marital status at a given age, and the health status at that age is added as a control to mitigate the fact that healthier 
individuals might have a higher likelihood of getting married in the first place. Murray (2000), who follow a sample of male graduates from Amherst College in Massachusetts, finds evidence for selection into marriage by health as well as protective effect of marriage on health outcomes. An alternative approach is to find valid instruments that generate exogenous variation in health or marriage outcomes. However, finding such instruments in not an easy task (Adams et al., 2003). Lillard and Panis (1996), using data only on males from the PSID and taking a simultaneous equations (instrumental variables) approach, find that there might be negative selection into marriage as less healthy men have more to gain from marriage. Pijoan-Mas and Ríos-Rull (2012) estimate, using the Health and Retirement Study (HRS), age-specific survival probabilities conditional upon socio-economic characteristics and show that married females (males) are expected to live 1.2 (2.2) years longer than their single counterparts. In this paper, we study self-reported health status for younger (20 to 64) individuals, we identify non-parametrically the marriage health gap as a function of age, and we account for self-selection into marriage based on innate permanent health.

There is also a growing literature in labor economics and macroeconomics that introduce health shocks and expenditures into life-cycle models with heterogeneous agents. French (2005), De Nardi, French and Jones (2010), Ozkan (2013), and Kopecky and Koreshkova (2014) are recent examples from this literature.

\section{Data and Descriptive Statistics}

We use two data sources to document the relationship between marriage and health. The first data source is the Panel Study of Income Dynamics (PSID). The PSID began in 1968 with a nationally representative sample of over 18,000 individuals living in 5,000 families in the United States. Extensive demographic and economic data on these individuals and their descendants have been collected continuously since then. Starting in 1984, the PSID has been collecting data on self-reported health of individuals. We use data from 1984 to 2011. The data is annual until 1997 and biannual afterward. Panel A of Table B1 in Appendix B shows descriptive statistics for the PSID sample.

The main health variable we use in this analysis is self-rated health. ${ }^{5}$ Each respondent is asked to rate their health as excellent, very good, good, fair, or poor. We consider those with excellent, very good or good health as healthy and others as unhealthy. As Table B1 shows, throughout the sample period, about $89 \%$ of individuals are healthy according to this definition. Likewise, about $65 \%$

\footnotetext{
${ }^{5}$ Bound (1991) discusses the implications of using subjective and objective health measures.
} 


\begin{tabular}{|c|c|c|c|c|c|c|c|c|}
\hline \multicolumn{9}{|c|}{ A. Marriage Ratios } \\
\hline & \multicolumn{2}{|c|}{ Married } & \multicolumn{2}{|c|}{ Divorced/Sep. } & \multicolumn{2}{|c|}{ Widowed } & \multicolumn{2}{|c|}{ Never Married } \\
\hline & PSID & MEPS & PSID & MEPS & PSID & MEPS & PSID & MEPS \\
\hline $20-24$ & 37.4 & 16.4 & 7.3 & 2.5 & 0.1 & 0.0 & 55.1 & 81.1 \\
\hline $25-29$ & 52.9 & 43.4 & 11.0 & 7.3 & 0.2 & 0.2 & 35.9 & 49.1 \\
\hline $30-34$ & 63.5 & 60.3 & 14.5 & 10.8 & 0.5 & 0.2 & 21.5 & 28.7 \\
\hline $35-39$ & 69.2 & 65.2 & 16.1 & 14.9 & 0.7 & 0.6 & 14.0 & 19.4 \\
\hline $40-44$ & 70.8 & 66.2 & 17.8 & 18.4 & 0.9 & 1.1 & 10.5 & 14.4 \\
\hline $45-49$ & 71.0 & 68.0 & 19.3 & 19.8 & 1.2 & 1.8 & 8.5 & 10.5 \\
\hline $50-54$ & 72.9 & 68.8 & 17.5 & 20.2 & 2.5 & 2.8 & 7.1 & 8.2 \\
\hline $55-59$ & 74.9 & 69.1 & 15.9 & 19.3 & 3.8 & 5.0 & 5.4 & 6.5 \\
\hline $60-64$ & 75.4 & 68.2 & 13.9 & 17.1 & 6.4 & 9.7 & 4.2 & 4.9 \\
\hline
\end{tabular}

B. Transitions In and Out of Marriage

\begin{tabular}{ccc} 
& $\begin{array}{c}\text { Married to } \\
\text { Unmarried }\end{array}$ & $\begin{array}{c}\text { Unmarried } \\
\text { to Married }\end{array}$ \\
\hline $20-24$ & 5.7 & 14.3 \\
$25-29$ & 4.7 & 12.4 \\
$30-34$ & 3.6 & 10.8 \\
$35-39$ & 2.8 & 8.0 \\
$40-44$ & 2.3 & 6.9 \\
$45-49$ & 1.8 & 5.2 \\
$50-54$ & 1.7 & 4.9 \\
$55-59$ & 1.5 & 2.3 \\
$60-64$ & 1.7 & 2.1 \\
\hline
\end{tabular}

Note: The table presents the weighted proportion of individual-year observations in each of four marital situations (A), and the proportion of married individuals getting unmarried in the following year and of unmarried individuals transiting into marriage (B), within five-year age groups. Panel A is computed using the PSID and the MEPS as indicated; in Panel B, the PSID is used. PSID sample covers 19842011, annually until 1997, biannually since then; MEPS sample covers 1996-2009 annually. One-year transitions in Panel B are computed for the period in which yearly observations are available. Data construction and variable definitions are described in Appendix A.

of individuals are married. We consider those who declare themselves married in the surveys as married and others (never married, divorced or widowed, separated, as well as cohabitants) as unmarried. In the sample, about $38 \%$ of individuals have a college degree. Per-adult household income is about 38,000 in 2005 U.S. dollars.

The second data source is the Medical Expenditure Panel Survey (MEPS). The MEPS is a set of surveys of families and individuals, their medical providers, and employers across the U.S. and is the most complete source of data on the cost and use of health care and health insurance coverage. The MEPS has two major components: the Household Component and the Insurance Component. The Household Component, which is used in the current analysis, provides data from individual households and their members, which is supplemented by data 
Figure 1. Health and Marital Status (PSID and MEPS)

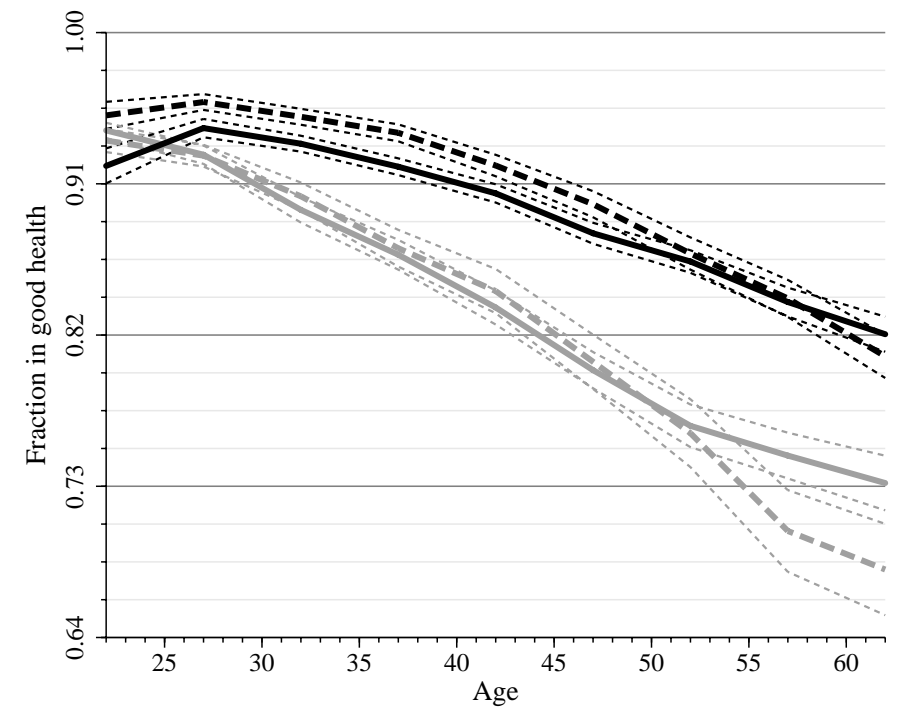

Note: Plotted lines represent the weighted fraction of married (black) and unmarried (gray) individuals that report being healthy, computed using the PSID (solid) and the MEPS (dashed). The horizontal axis indicates age, which is grouped in five-year categories (20-24, 25-29, 30-34, 35-39, 40-44, 45-49, 50$54,55-59$, and 60-64). Dotted lines around point estimates indicate confidence bands of \pm two standard errors, which are computed according to the corresponding survey design: sample weights are used for the PSID, and Taylor linearized standard errors are computed for the MEPS. Data construction and variable definitions are described in Appendix A.

from their medical providers. The Household Component contains detailed information for each person in the household on demographic characteristics, health conditions, health status, usage of medical services, charges and source of payments, access to care, satisfaction with care, health insurance coverage, income, and employment. The MEPS is a rotating panel where panel members are interviewed 5 times over a 2-year interval. In the analysis below we use pooled data from panels covering 1996-2009 period. Panel B of Table B1 in Appendix B presents descriptive statistics for the MEPS sample. As in the PSID, health status is self-reported (excellent, very good, good, fair, or poor), and we construct a binary variable for healthy vs unhealthy individuals. On average $88 \%$ of individuals report to be in excellent, very good, or good health, which is very close to the fraction of healthy individuals in the PSID. The MEPS and the PSID samples are quite similar in terms of education and household income. A smaller fraction of the MEPS sample is married, which reflects the facts that it covers relatively more recent years than the PSID does. About $16 \%$ of individuals in the MEPS sample do not have any, public or private, insurance. Individuals on average spend about $3,000 \$$ per year on health, which is about $9 \%$ of their total income.

Table 1 documents the marital status of the population in the PSID and MEPS samples (Panel A) and marital transitions in the PSID (Panel B). In both samples, almost all individuals eventually marry. Only about $4 \%$ to $5 \%$ of individuals 
Figure 2. Health and Marital Status for Different Socioeconomic Groups

A. Male vs female

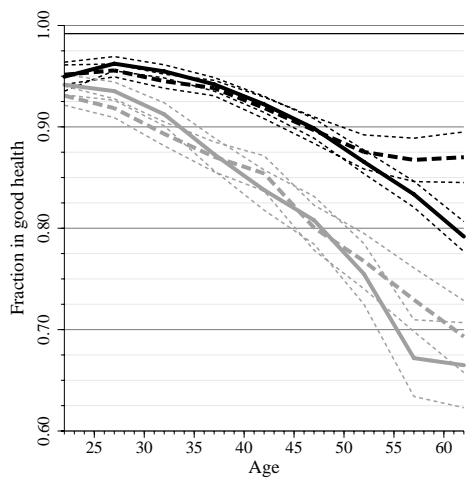

D. College vs non-College

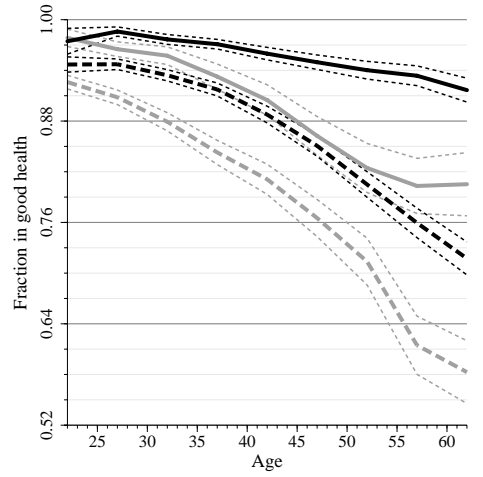

B. White vs black

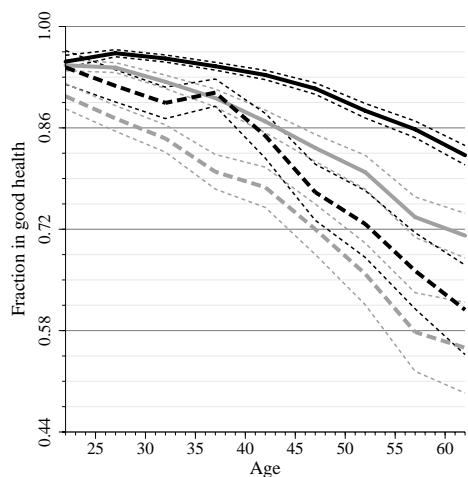

C. Without vs with children (0-12)

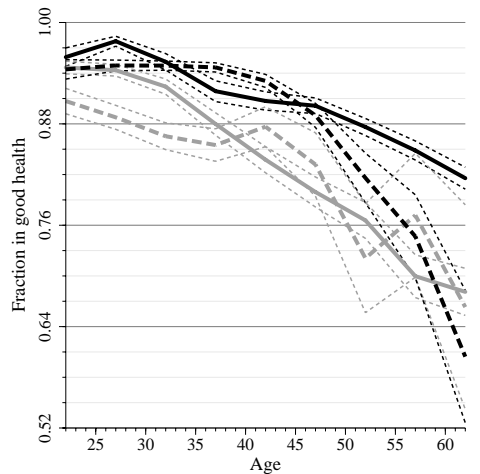

E. Above vs below median income

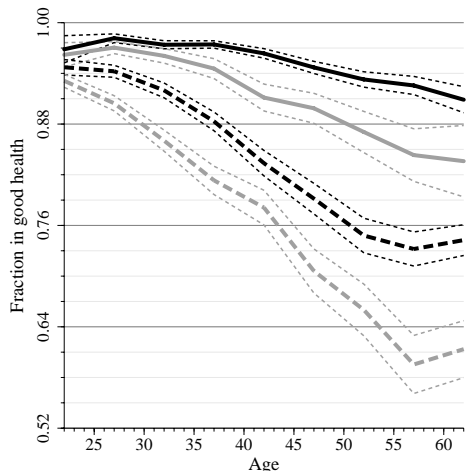

Note: Plotted lines represent the weighted fraction of married (black) and unmarried (gray) individuals that report being healthy, obtained from the PSID. Fractions are reported for: A. male (solid) and female (dashed), B. white (solid) and black (dashed), C. without (solid) and with (dashed) children aged 0-12 living in the household, D. college graduates (solid) and non-college (dashed), and E. above (solid) and below (dashed) median income. The horizontal axis indicates age, which is grouped in fiveyear categories (20-24, 25-29, 30-34, 35-39, 40-44, 45-49, 50-54, 55-59, and 60-64). Dotted lines around point estimates indicate confidence bands of \pm two standard errors, which are computed using sample weights. Data construction and variable definitions are described in the Appendix A, and a similar figure computed using the MEPS is presented in Appendix C.

remain never-married by ages 60-64. The fractions of individuals who are married, divorced or widowed increase monotonically by age. The fraction of people who are married in younger ages is larger in the PSID, which, as we commented above, reflects the fact that the MEPS covers more recent years than the PSID. For younger ages, there is significant turnover in marital status (Panel B). About 5\% of married individuals between ages 25 to 29 become unmarried each year (mainly divorced), and about $12 \%$ of singles in the same age group get married. The size of marital transitions declines as individuals age.

Figure 1 shows differences between married (black lines) and unmarried (gray lines) individuals in self-reported health from the PSID (dashed lines) and the MEPS (solid lines) for ages between 20 and 64. Age patterns of self-reported health as well as the health gap between married and unmarried agents are remarkably similar in the two data sets. On average for all ages considered (20-64), 
$91 \%$ of married individuals indicate that they are healthy, while only $86 \%$ of unmarried ones do so. Not surprisingly, in very early ages most individuals (more than $90 \%$ ) are in good health and the marriage health gap is small. For older ages the marriage health gap widens, and among those who are 40 to 64 years old, $88 \%$ of married individuals are healthy in contrast to $78 \%$ of unmarried ones.

The fact that married agents are healthier than single ones could be due to a host of factors. Figure 2 reproduces Figure 1 conditional on a few observable characteristics for the PSID sample. ${ }^{6}$ In each sub-panel, black lines indicate married individuals while gray lines are for unmarried ones, and solid and dashed lines indicate different sub-populations. As Panel A of Figure 2 shows, males and females report very similar levels of health when they are married or single. According to Panel B, blacks have on average worse health than whites and the marriage health gap vanishes for blacks at older ages. In Panel $\mathrm{C}$, the marriage health gap is visible and comparable whether or not one conditions on the presence of young (ages 0 to 12) children (estimates become imprecise at older ages, because few of those individuals have young children). Consistent with findings from the previous literature, individuals with better education and income have much better health. While the marriage health gap is similar conditional on college education (Panel D), the gap is larger for poorer individuals (Panel E).

\section{Model Specification and Identification}

In this section we describe our empirical strategy and discuss briefly how we identify the effect of marriage on health. The equation that we estimate is given by

$$
h_{i t}=\alpha\left(a_{i t}\right)+\beta\left(a_{i t}\right) m_{i t}+\boldsymbol{x}_{i t}^{\prime} \boldsymbol{\gamma}+\delta_{t}+\left(\eta_{i}+\varepsilon_{i t}\right),
$$

for $i=1, \ldots, N$ and $t=1, \ldots, T$, where $h_{i t}$ is the health status of individual $i$ in year $t, \alpha\left(a_{i t}\right)$ is the health curve for this individual when single, as a function of her age $a_{i t}, m_{i t}$ is an indicator variable that equals one whenever the individual is married, $\alpha\left(a_{i t}\right)+\beta\left(a_{i t}\right)$ is, thus, the health curve for the individual when married, $\boldsymbol{x}_{i t}$ is a vector that includes a set of control variables, $\delta_{t}$ indicates year dummies, and $\left(\eta_{i}+\varepsilon_{i t}\right)$ is the error term, unobserved by the econometrician. Our main object of interest is the marriage health gap $\beta(a)$.

The unobserved error term includes an individual-specific innate permanent component $\eta_{i}$, which is potentially correlated with marital status at different ages. This correlation can be generated by self-selection into marriage. Studies in evolutionary biology suggest that individuals with better innate health are

\footnotetext{
${ }^{6}$ The results for the MEPS sample are in Figure C1 in Appendix C.
} 
more attractive mates in the marriage market, as better health is a clear indication of reproductive success. This is summarized in Buss (1994) as follows: "Our ancestors had access to two types of observable evidence of a woman's health and youth: features of physical appearance, such as full lips, clear skin, smooth skin, clear eyes, lustrous hair and good muscle tone, and features of behavior, such as bouncy, youthful gait, and animated facial expression, and a high energy level. These physical cues to youth and health, and hence reproductive capacity, constitute the ingredients of male standards of female beauty" (p.53). ${ }^{7}$ In the presence of such selection, least squares estimates for equation (1) would deliver an overestimate of the marriage health gap. Furthermore, the size of the bias would differ at different ages. Since almost all individuals eventually get married at some point, the bias is likely to be larger at younger ages.

We illustrate this bias in Figure 3. Consider the data generating process described in Figure 3A, which shows health curves for married (black line) and single (gray line) individuals. The curves are drawn with $\boldsymbol{x}=\overline{\boldsymbol{x}}, \eta=0$, and $\varepsilon=0$. As Figure $3 \mathrm{~A}$ shows, this process does not generate a marriage health gap at younger ages, while it generates a marriage gap in later years. Our choice for particular health curves in Figure 3A is not random; they reproduce the marriage health gap we obtain from a within-groups estimation of equation (1) on the PSID sample. Note that, in equation (1), innate health $\eta$ enters as an additive shifter. Therefore, for given $\boldsymbol{x}_{i t}$ and $\varepsilon_{i t}$, different individuals are represented by health curves that are parallel to those in Figure $3 \mathrm{~A}$, and shifted by the corresponding $\eta_{i}$.

Figure 3B shows a simulated sample of 10 individuals generated by the process just described. Each individual is indicated by a different marker. There is, for example, an individual with the highest value of $\eta$ who is always married (marked by black squares at the top), and another individual with the lowest value of $\eta$ who is always single (marked by empty gray diamonds at the bottom). In between, there are individuals with different marital histories. The individual, who is indicated by empty circles, for example, is single before age 45 and then he/she gets married. In the generated sample, there is positive self-selection as individuals with higher $\eta$ are more likely to get married and do so earlier.

If we average observed health of married and of singles (or, equivalently, we fit equation (1) to those data by ordinary least squares (OLS)), we obtain the health curves depicted in Figure 3C. Given the selection into marriage by high $\eta$

\footnotetext{
7 Pointing in the same direction: "From the point of view of a female trying to pick good genes with which to ally her own, what is she looking for? One thing she wants is evidence of ability to survive" (Dawkins, 1989, p.157).
} 
Figure 3. Unobserved Heterogeneity and the Self-Selection Bias: An Example

A. Data generating process

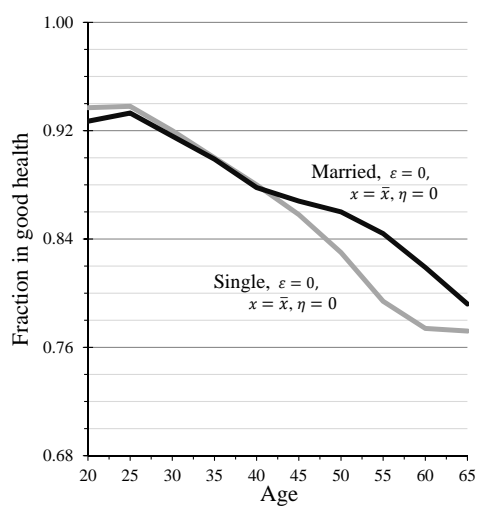

B. A sample of 10 individuals

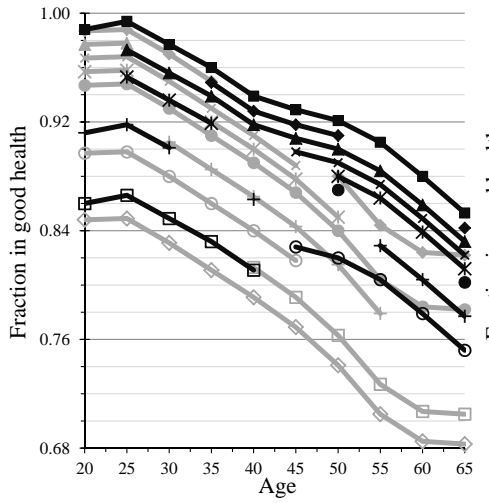

C. OLS estimates

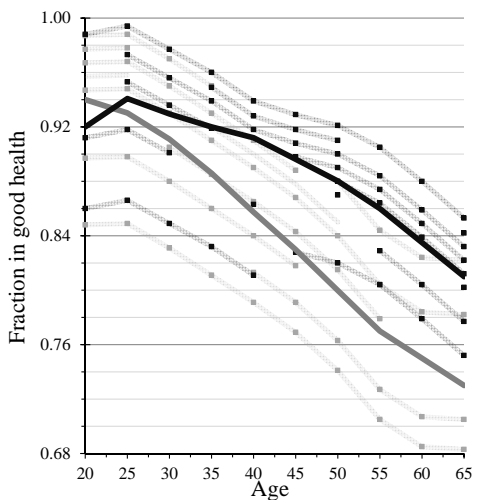

Note: Panel A presents married (black) and single (gray) health curves that constitute the data generating process. Panel B plots a sample of 10 observations simulated from the data generating process. Each marker identifies an individual. Health curves are plotted in gray when the individual is single, and in black when married. Panel C presents OLS estimates of the married and single health curves. Covariates $\boldsymbol{x}$ and i.i.d. shocks $\varepsilon$ are normalized to averages.

individuals, OLS overestimates the underlying marriage health gap. The health curves obtained in Figure 3C intentionally replicate the average health curves by marital status obtained from the PSID, depicted in Figure 1 in Section II.

In the empirical analysis below, we identify the single's health curve $\alpha(a)$ and the marriage health gap $\beta(a)$ non-parametrically. A within-groups estimation of equation (1) provides consistent estimates of the health curves, as long as our assumption of additive separability of $\eta$ is satisfied. It is very important to note that since $\alpha(a)$ and $\beta(a)$ are time-varying for a given individual, as he/she is observed over different ages, identification does not rely exclusively on individuals who change their marital status. Individuals contribute to the identification of the married health curve whenever they are married, even if they never switch marital status, up to a normalization of the intercept. Likewise, whenever they are single, individuals contribute to the identification of the single health curve up to the intercept. Marital status changes thus identify the gap between single and married intercepts. ${ }^{8}$ Consequently, identification of the marriage health gap at a given age, say 60 to 64 , is not identified exclusively by individuals who switch marital status within that age range.

We also estimate heterogeneous health curves that depend on socioeconomic characteristics. In particular, we estimate the following version of equation (1):

$$
h_{i t}=\alpha\left(a_{i t}, q_{i t}\right)+\beta\left(a_{i t}, q_{i t}\right) m_{i t}+\boldsymbol{x}_{i t}^{\prime} \boldsymbol{\gamma}+\delta_{t}+\left(\eta_{i}+\varepsilon_{i t}\right),
$$

8 Therefore, individuals who are, for example, always married (like the individual with the highest $\eta$ in Figure 3B) contribute to the identification of the shape of the married health curve, despite not contributing to the identification of the gap between married and single intercepts. 
for $i=1, \ldots, N$ and $t=1, \ldots, T$, where the health curves $\alpha(a, q)$ and $\alpha(a, q)+\beta(a, q)$ are now allowed to vary across different socioeconomic groups, denoted by $q$. In particular, motivated by the results in Figure 2, we estimate equation (2) for males vs females, blacks vs whites, individuals with vs without children, individuals with vs without a college degree, and individuals whose household income lies above vs below the median household income.

\section{Results}

In this section we present our estimates of the marriage health gap, $\beta(a)$ in equation (1). We first present OLS and within-groups estimates. We also show that the main results are robust to different definitions of two key variables, health and marriage. Finally, we report the marriage health gap conditional on observable characteristics, $\beta(a, q)$ in equation (2).

\section{A. Main Results}

Figure 4 presents OLS estimates of $\beta(a)$ from the PSID (black) and the MEPS (gray) samples. ${ }^{9}$ In the estimation of equation (1), we use five-year age bins, from $20-24$ to $60-64 .{ }^{10}$ Health, $h$, is an indicator variable that takes a value of one whenever the individual is healthy. Control variables, $\boldsymbol{x}$, include income, gender (female dummy), race (black dummy), education (college dummy), and children (dummies for presence of children ages 0-3, 4-12, and 13-18 in the household).

The results show that after controlling for observable characteristics, there is a positive and significant difference between the reported health of married and unmarried individuals. The gap is about 1 percentage point for younger (20-24) ages, and increases monotonically to around 12 percentage points for 55 to 59 age group in the PSID sample. Similar results are obtained from the MEPS sample when we estimate the model with the same controls. The gap is initially small and grows to about 8 percentage points for 55 to 59 age group.

Figure 5 shows within-groups estimates (black line) together with OLS estimates from Figure 4 (gray line) for the PSID sample. Within-groups estimation reduces the size of the marriage health gap substantially. Indeed for ages up to 40 the marriage health gap disappears completely. After age 40, however, the positive effect of marriage on health starts to show up. At the peak of the gap (between ages 55 and 59), married individuals are about 6 percentage points more likely

\footnotetext{
9 The full set of regression coefficients are shown in Table B2 in Appendix B.

${ }^{10}$ Results shown below are robust across different bin widths. Whenever they are presented in figures, the mid point of the age interval is plotted.
} 


\section{Figure 4. Health and Marital Status: OlS Estimation Results}

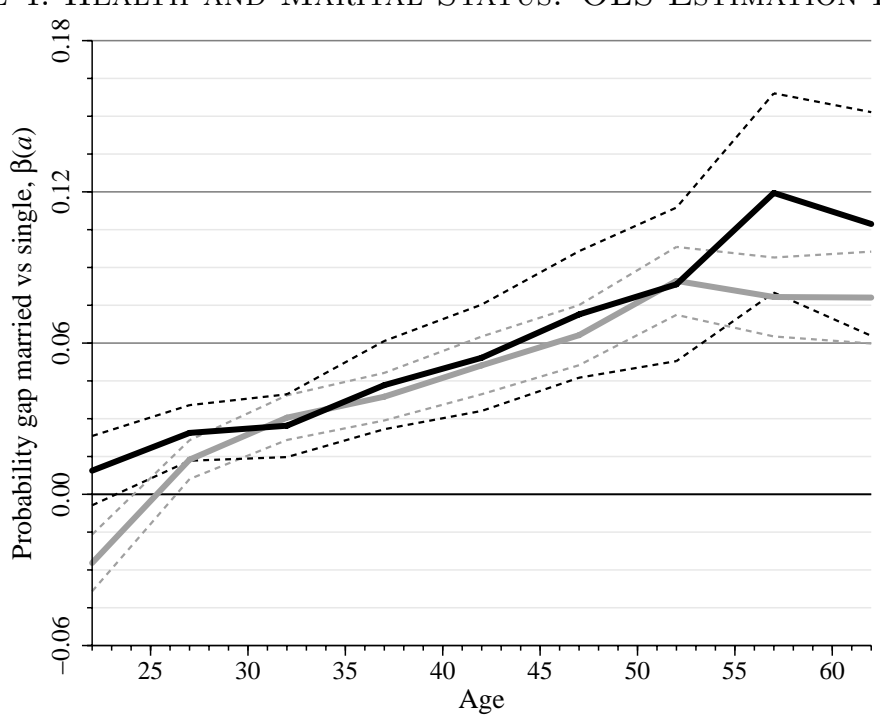

Note: Solid lines are OLS estimated marriage health gaps, $\beta(a)$. The regression is fitted to the PSID (black) and the MEPS (gray). The dependent variable, $h$, is an indicator variable that takes a value of one whenever the agent is healthy. Control variables, $\boldsymbol{x}$, include income, gender (female dummy), race (black dummy), education (college dummy), children (dummies for 0-3, 4-12, and 13-18 year-old children), and survey year (year dummies); regressions also estimate $\alpha(a)$. The horizontal axis indicates age. In estimation, five-year age bins (20-24, 25-29, 30-34, 35-39, 40-44, 45-49, 50-54, 55-59, and 60-64) are considered. The center point of the bin is represented in the figure. Cross-sectional weights are used in estimation. Dotted lines indicate \pm two standard errors confidence bands around point estimates, which are clustered at the household level in the PSID, and Taylor linearized using survey stratification design in the MEPS. Data construction and variable definitions are described in Appendix A.

\section{Figure 5. Health and Marital Status: Within-Groups Estimation Results}

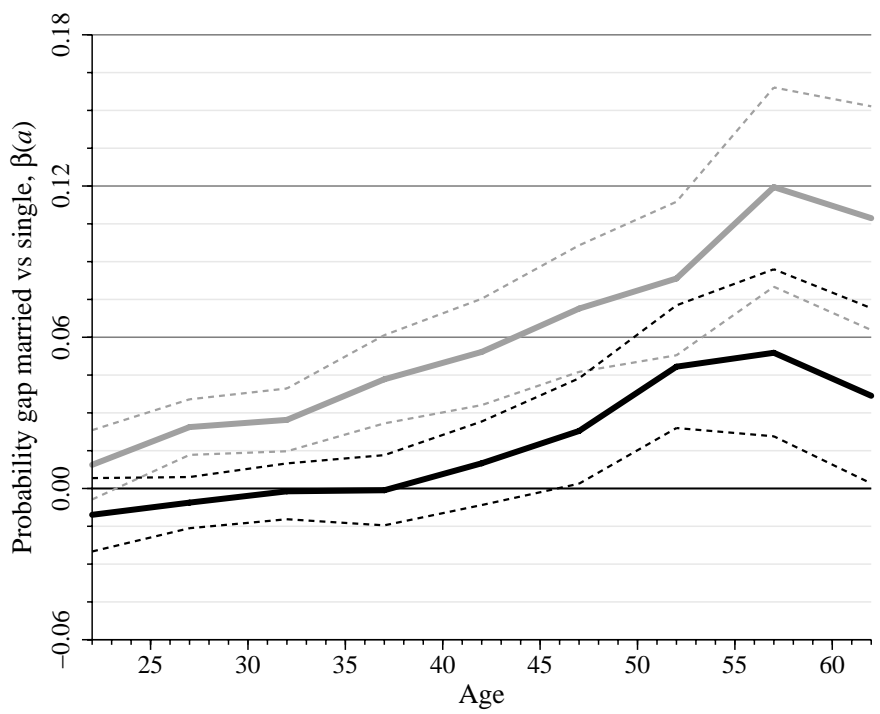

Note: Solid lines are within-groups (black) and OLS (gray) estimated marriage health gaps, $\beta(a)$. The regression is fitted to the PSID. The dependent variable, $h$, is an indicator variable that takes a value of one whenever the agent is healthy. Control variables, $\boldsymbol{x}$, include income, gender (female dummy), race (black dummy), education (college dummy), children (dummies for 0-3, 4-12, and 13-18 year-old children), and survey year (year dummies); regressions also estimate $\alpha(a)$. The horizontal axis indicates age. In estimation, five-year age bins (20-24, 25-29, 30-34, 35-39, 40-44, 45-49, 50-54, 55-59, and 60-64) are considered. The center point of the bin is represented in the figure. Weights are used in estimation. Dotted lines indicate \pm two standard errors confidence bands around point estimates, which are clustered at the household level. Data construction and variable definitions are described in Appendix A. 
to be healthy than unmarried ones. This is about half of the OLS estimated gap. These results suggests that there is an important role for self-selection in explaining the observed marriage health gap, especially at earlier ages, while some protective effects of marriage on health remain at older ages. We explore both self-selection patterns and the potential remaining effect of marriage on health in further detail in Section V.

\section{B. Robustness}

The results in Figure 4 and Figure 5 are based on self-reported measures of health. The MEPS contains another measure, SF12v2 (short form 12 version 2), that is constructed as an index by the interviewers from answers that respondents give to a set of health-related questions. The left panel of Figure 6 replicates the OLS estimates from the MEPS sample with this objective measure of health, and show that the basic qualitative picture remains the same. Another measure of health is the presence of chronic conditions (such as cancer, hypertension, diabetes, stroke, hearth attack, etc.), which is provided in the PSID. The right panel of Figure 6 shows the within-groups estimates of the marriage gap on the number of different chronic conditions an individual ever had by any given age. Consistent with other two measures of health, the difference between married and single individuals is very small for younger ages, but as individuals age, married individuals have a much smaller number of chronic conditions than singles do. Around ages 50 to 54, for example, being married is associated with 0.1 fewer chronic conditions. As we document in Table B1, on average individuals have about 0.65 chronic conditions. Hence, the marriage gap is about $15 \%$ of the mean.

We also check whether the way we define married and unmarried individuals affect the results. In our first check, we would like to understand whether divorce (in contrast to being never married) has a particularly adverse effect on health. To this end, we drop divorced agents from the pool of unmarried, and compare married individuals with those who are never married or widowed. Results, shown in Panel A of Figure 7, are very much in line with our basic results. Indeed, the marriage health gap is now slightly larger, which suggests that divorced individuals have better, not worse, health than those who are never married or widowed. As we discuss below, this possibly reflects the positive effects of marriage capital (measured as the total number of years one is married) on health. Next, we exclude widows from the pool of single agents (Panel B). In this case, results are similar to our baseline results. As a final check, we consider all cohabitants as married (Panel C). As documented in Table B1, this increases the fraction of 


\section{Figure 6. Alternative Health Measures}

A. MEPS objective health index

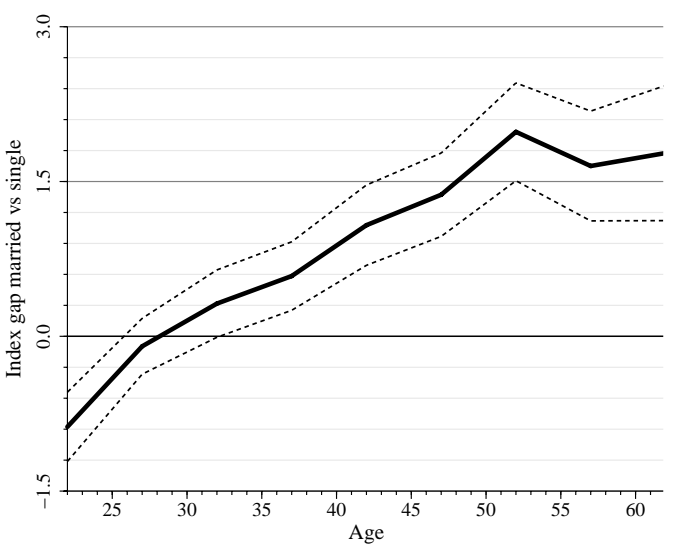

B. Chronic conditions

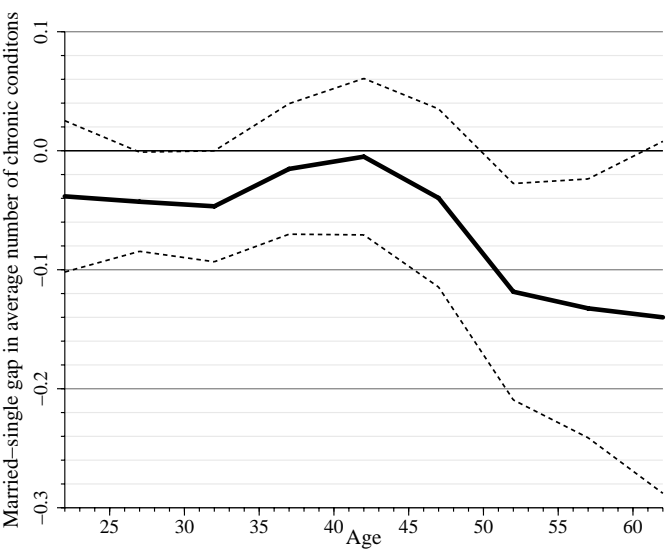

Note: Plotted lines represent marriage health gaps, $\beta(a)$, for two alternative measures of health, $h$ : SF12v2 objective index of health (Panel A), estimated by OLS from the MEPS, and the cumulative number of different chronic conditions suffered by the individual (Panel B), which are within-groups estimates from the PSID. Control variables, $\boldsymbol{x}$, include income, gender (female dummy), race (black dummy), education (college dummy), children (dummies for 0-3, 4-12, and 13-18 year-old children), and survey year (year dummies); regressions also estimate $\alpha(a)$. The horizontal axis indicates age. In estimation, five-year age bins (20-24, 25-29, 30-34, 35-39, 40-44, 45-49, 50-54, 55-59, and 60-64) are considered. The center point of the bin is represented in the figure. For objective health, OLS estimates are provided, given the unavailability of a long enough panel. For chronic conditions, within-groups estimates are provided. The following chronic conditions are considered: stroke, heart attack, hypertension, diabetes, cancer, lung disease, arthritis, asthma, memory loss, and learning disorder, as defined in the PSID. Dotted lines indicate \pm two standard errors confidence bands around point estimates, which are clustered at the household level in the PSID, and Taylor linearized using survey stratification design in the MEPS. Data construction and variable definitions are described in Appendix A.

\section{Figure 7. Marriage, Cohabitation, Divorce, and Widowhood}

\section{A. Divorced/separated excluded}

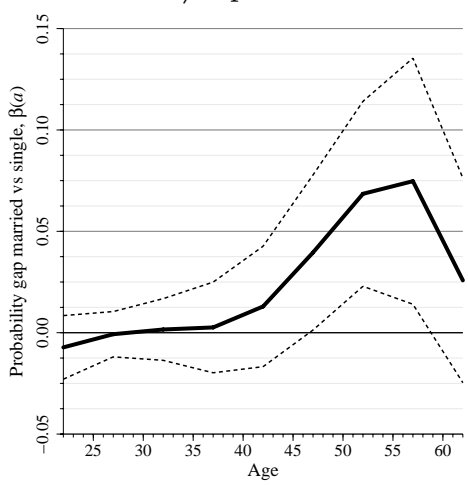

B. Widowed excluded

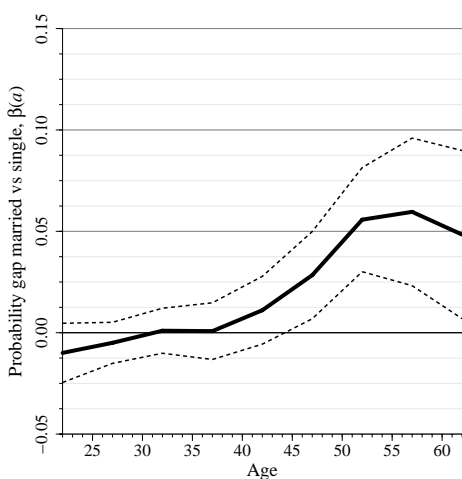

C. Cohabiting incl. in married

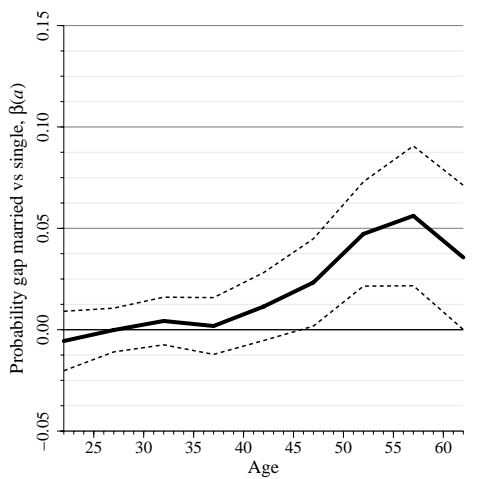

Note: Solid lines are within-groups estimated marriage health gaps, $\beta(a)$, for different definitions of married and unmarried populations: excluding divorced/separated (Panel A) or widowed (Panel B) from the sample, and including cohabitants in the married group (Panel C). The regression is fitted to the PSID. Control variables, $\boldsymbol{x}$, include income, gender (female dummy), race (black dummy), education (college dummy), children (dummies for 0-3, 4-12, and 13-18 year-old children), and survey year (year dummies); regressions also estimate $\alpha(a)$. The horizontal axis indicates age. In estimation, five-year age bins (20-24, 25-29, 30-34, 35-39, 40-44, 45-49, 50-54, 55-59, and 60-64) are considered. The center point of the bin is represented in the figure. Weights are used in estimation. Dotted lines indicate \pm two standard errors confidence bands around point estimates, which are clustered at the household level. Data construction and variable definitions are described in Appendix A. 


\section{Figure 8. Heterogeneous Effects Across Socioeconomic Groups}

\section{A. Male vs female}

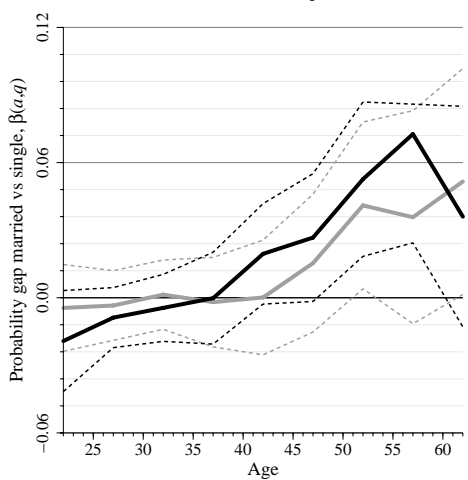

D. College vs non-College

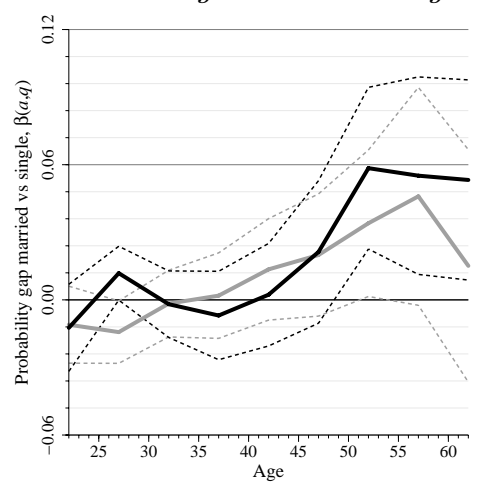

B. White vs black

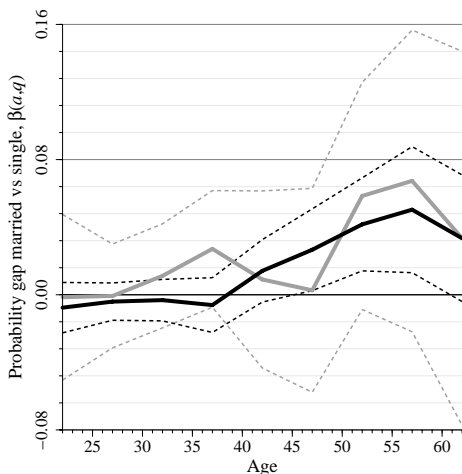

C. Without vs with children (0-12)

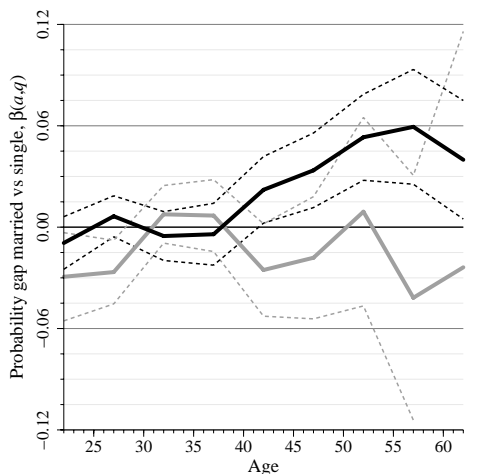

E. Above vs below median income

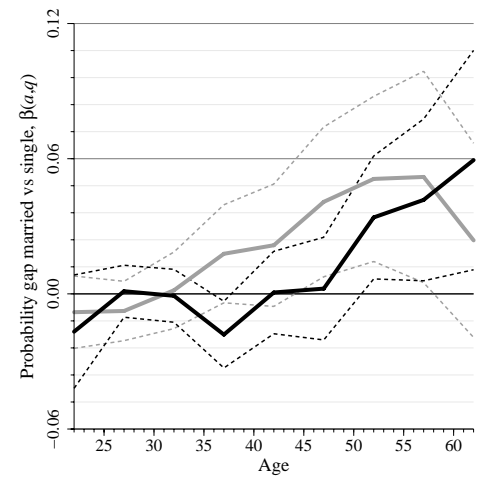

Note: Solid lines are within-groups estimated marriage health gaps for different subpopulations, $\beta(a, q)$. Regressions are fitted to the PSID. The following subpopulations are considered: A. male (black) vs female (gray), B. white (black) vs black (gray), C. without (black) vs with (gray) children aged 0-12, D. college (black) vs non-college (gray), and E. above (black) vs below (gray) median income. The dependent variable, $h$, is an indicator variable that takes a value of one whenever the agent is healthy. Control variables, $\boldsymbol{x}$, include income, gender (female dummy), race (black dummy), education (college dummy), children (dummies for presence of 0-3, 4-12, and 13-18 year-old children in the household), and survey year (year dummies); regressions also estimate $\alpha(a, q)$. The horizontal axis indicates age. In estimation, five-year age bins (20-24, 25-29, 30-34, 35-39, 40-44, 45-49, 50-54, 55-59, and 60-64) are considered. The center point of the bin is represented in the figure. Weights are used in estimation. Dotted lines indicate \pm two standard errors confidence bands around point estimates, which are clustered at the household level. Data construction and variable definitions are described in Appendix A.

married in the PSID from $65 \%$ to $72 \%$. Point estimates of the marriage health gap are now slightly smaller, but not statistically different from baseline results. ${ }^{11}$

\section{Heterogeneous Effects}

Next, we focus on the marriage health gap for different sub-populations and present within-groups estimates of $\beta(a, q)$ from equation (2). Panel A in Figure 8 shows that the marriage health gap is only slightly higher for men compared to

11 The slightly lower effect could be the result of cohabitants being more similar to unmarried individuals than to married ones. This would be consistent with Schoenborn (2004), who document that "health limitations, conditions, and unhealthy behaviors among adults living with a partner resembled or exceeded prevalence among adults who are divorced or separated." (p.11). 
women, and it is not statistically different. ${ }^{12}$ The marriage health gaps are also very similar for blacks and whites (Panel B), and for individuals with and without a college degree (Panel D). The comparison of individuals with and without young (0 to 12 years old) children (Panel C) delivers surprising results. Consistent with our baseline results, there does not exist any significant effect of marriage on health for either group before age 45 . After age 45, however, there is a significant marriage health gap for individuals who do not have young (ages 0 to 12) children. The estimates for individuals who have young children at home after age 45, on the other hand, are close to zero but very imprecise, as this is a rather small group. One way to make sense of these differences is to note that most of married individuals who do not have young children at home in their later ages are the ones who marry at a younger age, and hence they accumulated more marriage health capital. Finally, poorer individuals seem benefit more from marriage (Panel E).

\section{Selection and Protection}

Results in previous section suggest that both selection of healthy individuals into marriage as well as protection and improvement of health within marriage play a role in generating the observed marriage health gap in the data. In this section, we focus on possible ways selection and protection may show up in the data.

\section{A. Selection into Marriage and Assortative Mating by Health}

We start by documenting how innate permanent health is distributed among married and unmarried individuals. Table 2 shows innate health differences between individuals who are never and ever married by ages 30 and 40, measured by recovered individual fixed effects from equation (1). For both ages, the average innate health of ever-married individuals is higher than never-married ones, but there is more dispersion among never married. At age 30, for example, coefficient of variation of innate permanent health is about 7.4 and 14.2 for married and unmarried individuals, respectively. Dispersion among unmarried is even higher at age 40. Additionally, the innate health distribution of ever-married individuals dominates that of never-married ones at lower deciles (below fourth), while the reverse is true for higher deciles.

These patterns are consistent with selection of healthy individuals into marriage. Consider a world in which innate health is observable and singles look for healthy

\footnotetext{
12 The lack of gender differences in the marriage health gap is consistent with Lillard and Waite (1995) who find that the effect of marriage on mortality is similar for men and women. Much of the existing literature, however, see e.g. Williams and Umberson (2004), documents that effect of marriage on health is more important for males.
} 
Table 2 - Empirical Distribution of Innate Permanent Health $\left(\eta_{i}\right)$

\begin{tabular}{cccccc}
\hline \hline & \multicolumn{3}{c}{ Individuals observed at... } \\
\cline { 2 - 3 } & \multicolumn{2}{c}{ Age 30} & & \multicolumn{2}{c}{ Age 40} \\
\cline { 2 - 3 } \cline { 5 - 6 } & $\begin{array}{c}\text { Never } \\
\text { married }\end{array}$ & $\begin{array}{c}\text { Ever } \\
\text { married }\end{array}$ & & $\begin{array}{c}\text { Never } \\
\text { married }\end{array}$ & $\begin{array}{c}\text { Ever } \\
\text { married }\end{array}$ \\
\cline { 2 - 3 } & & & & & \\
Summary measures: & 0.015 & 0.025 & & -0.028 & -0.013 \\
Mean & 0.213 & 0.184 & & 0.231 & 0.221 \\
Standard dev. & 2,163 & 5,808 & & 790 & 5,230 \\
Number of indiv. & & & & \\
\hline Deciles: & -0.252 & -0.174 & & -0.346 & -0.283 \\
1st & -0.046 & -0.003 & & -0.142 & -0.054 \\
2nd & 0.042 & 0.051 & & -0.032 & 0.032 \\
3rd & 0.078 & 0.072 & & 0.048 & 0.057 \\
4th & 0.096 & 0.084 & & 0.078 & 0.074 \\
5th & 0.111 & 0.094 & & 0.101 & 0.084 \\
7th & 0.126 & 0.106 & & 0.109 & 0.094 \\
8th & 0.144 & 0.125 & & 0.118 & 0.105 \\
9th & 0.155 & 0.145 & & 0.129 & 0.119 \\
\hline \hline
\end{tabular}

Note: The table reports statistics that summarize the empirical distribution of recovered fixed effects $\left(\eta_{i}\right.$ in equation (1)) for different groups of individuals. Each block includes individuals that, at the indicated age, are in the indicated situation: never married or ever married. Statistics are computed from the PSID. Weights are used in the estimation. Three year windows are constructed around the indicated age to increase the number of observations.

partners. In such world, given large variance of health among never married individuals, those with good health wait until they find a suitable partner. As a result, the average innate health among married is higher, while the dispersion of health is smaller (as in our data). Those with bad health are unattractive partners in the marriage market and those with better health are more selective. Hence, in such a world, health is a good predictor of entry into marriage and there is positive assortative mating by health among married individuals. ${ }^{13}$ As we discuss in the following paragraphs, the data supports both of these predictions.

In Table 3, we explore whether health is a good predictor of entry into marriage in the PSID. We focus on individuals who remain unmarried by age 25 and analyze how their health in younger ages (captured by average health between ages 20-25, $h_{i, 20-25}$ ) and their innate permanent health (captured by the estimated fixed effect from equation $(1), \widehat{\eta}_{i}$ ) affect their probability of getting married between ages 30

13 There is evidence that husbands and wives sort by smoking behavior as well as by bodymass index. See Clark and Etile (2006), and Chiappori, Oreffice and Quintana-Domenque (2012, 2013). Domingue, Fletcher, Conley and Boardman (2014) compare genetic similarities between married and non-couple (random) pairs in the population and find genetic assortative mating. 
Table 3-The Effect of Health on the Probability of Getting Married

\begin{tabular}{|c|c|c|c|c|c|}
\hline & $(1)$ & $(2)$ & $(3)$ & $(4)$ & $(5)$ \\
\hline Health at age $20-25$ & $\begin{array}{c}0.196 \\
(0.079)\end{array}$ & $\begin{array}{c}0.013 \\
(0.110)\end{array}$ & $\begin{array}{l}-0.137 \\
(0.106)\end{array}$ & $\begin{array}{l}-0.149 \\
(0.109)\end{array}$ & $\begin{array}{c}-0.099 \\
(0.103)\end{array}$ \\
\hline Innate permanent health & & $\begin{array}{c}0.299 \\
(0.128)\end{array}$ & $\begin{array}{c}0.479 \\
(0.123)\end{array}$ & $\begin{array}{c}0.259 \\
(0.128)\end{array}$ & $\begin{array}{c}0.163 \\
(0.116)\end{array}$ \\
\hline College & & & & $\begin{array}{c}0.209 \\
(0.031)\end{array}$ & $\begin{array}{c}0.216 \\
(0.028)\end{array}$ \\
\hline Black & & & & $\begin{array}{l}-0.226 \\
(0.035)\end{array}$ & $\begin{array}{c}-0.276 \\
(0.033)\end{array}$ \\
\hline Female & & & & $\begin{array}{l}-0.027 \\
(0.028)\end{array}$ & $\begin{array}{l}-0.058 \\
(0.026)\end{array}$ \\
\hline Income (average $30-40$ ) & & & & & $\begin{array}{c}0.001 \\
(0.000)\end{array}$ \\
\hline Presence of kids (30-40) & & & & & $\begin{array}{c}0.423 \\
(0.029)\end{array}$ \\
\hline Constant & $\begin{array}{c}0.396 \\
(0.076)\end{array}$ & $\begin{array}{c}0.555 \\
(0.101)\end{array}$ & & & \\
\hline Cohort dummies: & No & No & Yes & Yes & Yes \\
\hline Observations & 1,700 & 1,700 & 1,700 & 1,700 & 1,700 \\
\hline Adj. R-squared & 0.005 & 0.010 & 0.611 & 0.644 & 0.705 \\
\hline
\end{tabular}

Note: The dependent variable takes the value of one if the individual is married at some point between age 30 and 40 . The sample is restricted to individuals who have never been married by age 25 . Health at age $20-25$ is the average health of the individual at that age range. Innate permanent health is the recovered fixed effect $\left(\widehat{\eta}_{i}\right)$ from equation (1); its standard deviation is 0.243 . Cohort of birth dummies are included when indicated. Robust standard errors in parenthesis.

and 40. In particular, we estimate the following regression:

$$
m_{i, 30-40}=\phi h_{i, 20-25}+\theta \widehat{\eta}_{i}+\boldsymbol{z}_{i, 30-40}^{\prime} \boldsymbol{\lambda}+v_{i, 30-40}
$$

where $m_{i, 30-40}$ equals one if individual (never married by age 25 ) is married at some point between ages 30 and $40, h_{i, 20-25}$ is individual's average health at ages 20 to 25 , $\widehat{\eta}_{i}$ is the recovered fixed effect from equation (1), and $\boldsymbol{z}_{i, 30-40}$ is a vector of controls.

Column 1 in Table 3 shows that an unmarried individual who is in good health between ages 20-25 has about 20 percentage points higher chances of being married at some point between ages 30 and 40 than someone whose health is poor. When we include innate permanent health in the regression, the latter absorbs all the positive association with marriage probability (column 2). In particular, a one standard deviation increase in innate permanent health is associated with a 7 percentage points increase in the probability of getting married before age 40; in this case, the remaining effect of being in good health at ages 20 to 25 is only 1 percentage point, and is not significant. When we add further controls (education, gender, race and income) the effect of innate permanent health remains 
Table 4-Marital Sorting: Correlation of Husband and Wife Fixed Effects

\begin{tabular}{lccc}
\hline \hline & $(1)$ & $(2)$ & $(3)$ \\
\hline Correlation & $\begin{array}{c}0.394 \\
(0.025)\end{array}$ & $\begin{array}{c}0.375 \\
(0.025)\end{array}$ & $\begin{array}{c}(0.331 \\
\end{array}$ \\
\hline Controls: & & & \\
College and race & No & Yes & Yes \\
Permanent income & No & No & Yes \\
\hline \hline
\end{tabular}

Note: The table reports conditional correlation coefficients of husband and wife's estimated innate health (i.e. recovered $\eta_{i}$ from within-groups estimation of equation (1)). College and race controls are dummies for individuals and spouses having a college degree and being black, as well as the corresponding interactions. Permanent income controls include husband's, wife's, and interacted fixed individual effects obtained from the within-groups estimation of a regression of taxable individual income on years of education, age, age squared, marriage, and year dummies. Correlations are estimated using data from the PSID. Weights are used in the estimation. One observation per available couple $(5,323)$ is included. Bootstrapped standard errors (with 200 repetitions) in parenthesis.

significant, whereas point estimates for the coefficient on past health become negative although imprecise (columns 3-5). These results suggest that selection into marriage is mostly captured by the individual fixed effects (and the controls), and that, if anything, the remaining effect of past health on marriage would be negative. Some of the results presented in Section V.B support the latter.

We also find evidence of a strong assortative mating by health among married individuals. Table 4 shows that the simple correlation coefficient between the innate permanent health of husbands and wives is about 0.4 (as a comparison, the simple correlation coefficient for years of education among husbands and wives is about 0.5 in the data). ${ }^{14}$ When we control for education and race (by regressing recovered innate health, $\widehat{\eta}_{i}$, on these controls and looking at the correlations between residuals), the correlation remains almost unchanged. Even when we add a measure of permanent income (recovered fixed effects from a regression of taxable individual income on education, age, age squared, marriage and year dummies) as a further control, innate permanent health is still highly correlated between husbands and wives (0.33).

\section{B. Health Accumulation Through Marriage}

We next turn to protective effects of marriage on health. We first investigate whether the benefits of marriage on health are cumulative, i.e. whether the duration of marriage matters. In Panel A of Figure 9, we show results from a regression that is very similar to equation (1) except that $m_{i t}$ is replaced by a measure of

\footnotetext{
${ }^{14}$ For the evidence on assortative mating by education and the related literature in economics, see Greenwood, Guner, Kocharkov and Santos (2014). Schwartz (2013) provides a review of the literature in sociology.
} 
Figure 9. Health Accumulation Through Marriage

A. Marriage capital

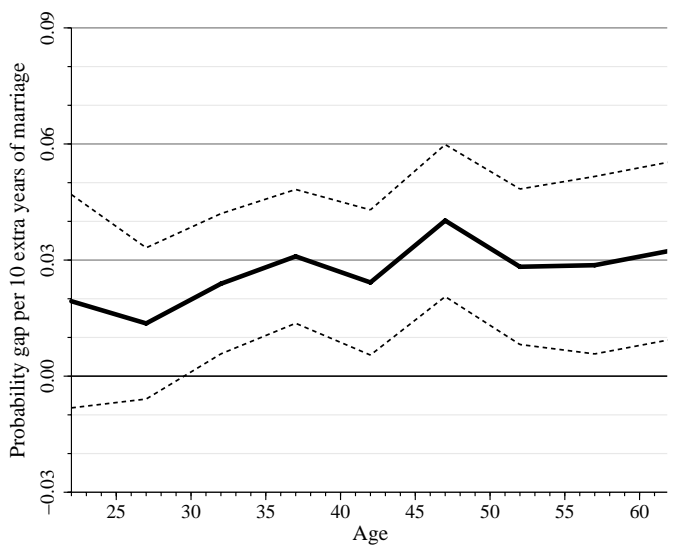

B. Dynamic model

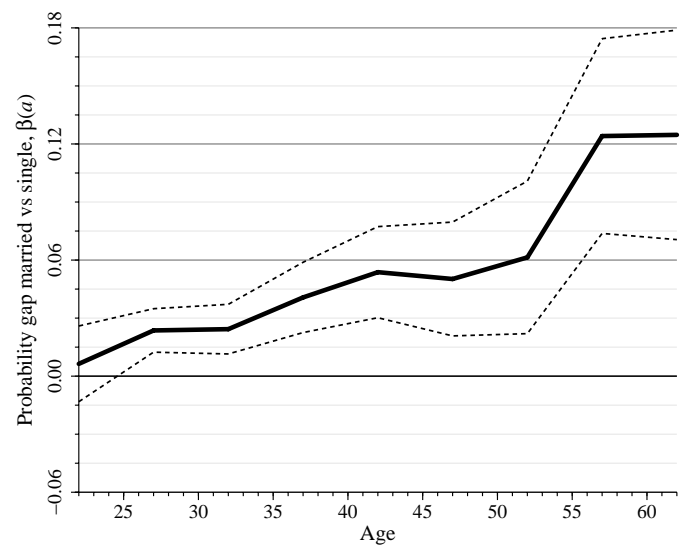

Note: The figure presents estimates of $\beta(a)$ from two modified versions of equation (1): one (Panel A) in which the married dummy, $m$ is replaced by the number of years an individual have been married (zero if never married); the other (Panel B) in which the model is expanded to include the lagged dependent variable $h_{t-1}$ as an additional control. Left figure is estimated using the within-groups estimator, right figure is estimated using System-GMM. Both models are estimated using data from the PSID. Control variables, $\boldsymbol{x}$, include income, gender (female dummy), race (black dummy), education (college dummy), children (dummies for 0-3, 4-12, and 13-18 year-old children), and survey year (year dummies); regressions also estimate $\alpha(a)$. The horizontal axis indicates age. In estimation, five-year age bins (20-24, 25-29, 30-34, 35-39, 40-44, 45-49, 50-54, 55-59, and 60-64) are considered. Dotted lines are \pm two standard errors confidence bands around point estimates, clustered at the household level.

marriage capital (defined as the total number of years an individual has been married by year $t) .{ }^{15}$ Hence $\beta(a)$ now measures the effect of one extra year of being married at a given age $a$ on the probability of being healthy. The effect of an extra year of marriage has a positive and significant effect on being healthy that is roughly constant after ages 35-39: 10 extra years of marriage capital increase the probability of being healthy by about 3 percentage points.

Given the importance of marriage health capital, we also estimate equation (1) with past health as an additional control variable. In this case, a within-groups estimation does not deliver consistent estimates (Arellano and Bond, 1991). Therefore, we use a generalized method of moments approach, in the way described in Arellano and Bover (1995) (often known as System-GMM). The results are presented in Panel B of Figure 9. While the overall pattern of the marriage health gap is similar to what we obtain from within-groups estimates, the marriage health gap is now larger. As we have shown in Table 3, after we net out individual fixed effects, there is a negative correlation between lagged health and the probability of getting married. As a result, by not including lagged health in equation (1), we underestimate the effect of marriage on health. Once this bias is corrected, the effect of marriage on health is estimated to be even larger. In Panel B of Figure 9,

\footnotetext{
${ }^{15}$ Independent of whether the person is married to the same partner.
} 
marriage heath gap is about $6 \%$ for ages 40 to 49 and increases up to $12 \%$ for later years. These results suggest that the baseline within-groups results in Figure 5, are, if anything, conservative estimates of the effect of marriage on health.

\section{Healthy Behavior}

What factors can explain the protective effect of marriage on health? In this section, we document that married individuals are much more likely to engage in healthy behavior than unmarried ones. Figure 10 shows differences between married and unmarried individuals in preventive health checks. The figure shows coefficients form regressions similar to equation (1), where the dependent variable is whether an individual performs a particular preventive check at a given age.

The results show that there are significant differences between married and single individuals for all categories of preventive care. Married individuals around ages 50 to 54, for example, are about $6 \%$ more likely to check their cholesterol or have a prostate or breast examination. Note that these differences come from regressions that control for education and income. Hence, the effect of marriage on healthy behavior goes beyond the well documented effect (see e.g. Cutler and Lleras-Muney, 2010) of education on healthy behavior.

Why would married individuals be more likely to do preventive care? One possible factor, which is well documented in the medical literature, is that having a partner encourages individuals to follow up on medical appointments, checkups, etc. ${ }^{16}$ Another factor, which we focus on in the next section, is the fact that married individuals are more likely to have health insurance than unmarried are.

Differences between married and unmarried individuals in healthy behavior are also reflected in their medical expenditures. To analyze differences in medical expenditures, we model the conditional median of the total medical expenditure in a way similar to equation (1) except that the dependent variable is now total medical expenditure. ${ }^{17}$ Panel A of Figure 11 shows our estimates of the marriage gap in median health expenditure estimated from the MEPS. Results suggest that median health expenditure of married individuals aged below 40 is around 40-60\$ larger per year than that of unmarried individuals at the same age range. At

\footnotetext{
16 There is a large medical literature that documents the link between marriage and specific health outcomes. In an interview to CNN, Dr. Paul L. Nguyen, summarizing research by Aizer et al. (2013), states that "You are going to nag your wife to go get her mammograms. You are going to nag your husband to go get his colonoscopy.... If you are on your own, nobody is going to nag you." In interview available at http://thechart.blogs.cnn.com/2013/09/23/ marriage-may-improve-cancer-survival-odds/?hpt=he_c2, accessed on December 6, 2013. See Waite and Gallagher (2000) for further evidence on what they call "the virtues of nagging".

17 Similarly, we consider regressions for mean expenditures as opposed to median, which deliver very similar results, with a different scale.
} 
Figure 10. Preventive Health Checks and Marital Status

A. Dental check

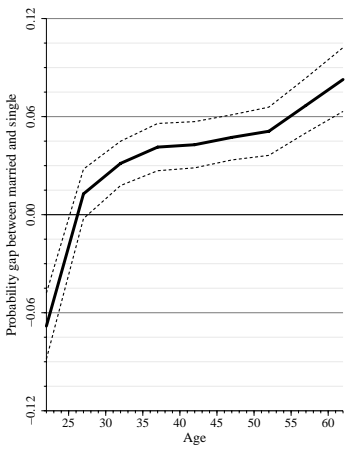

E. Prostate exam

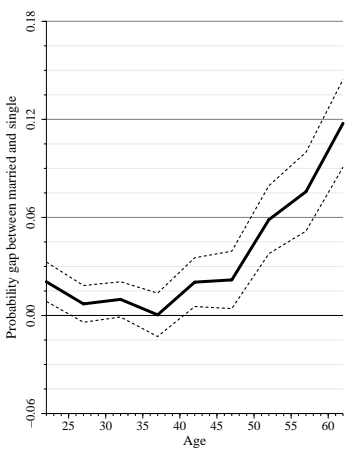

B. Cholesterol check

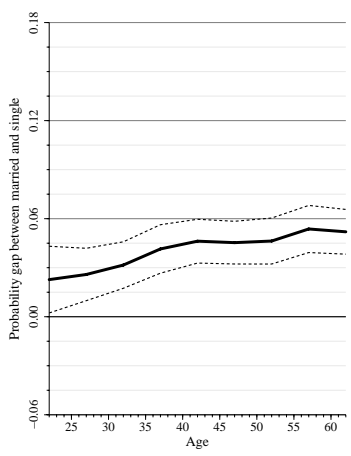

F. Pap smear

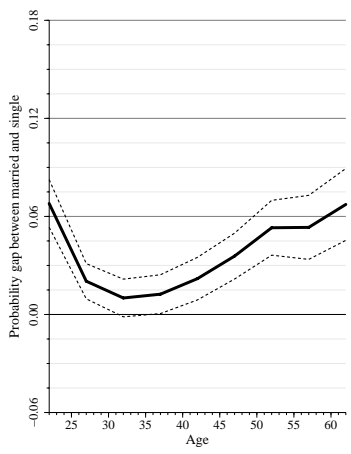

C. Complete check

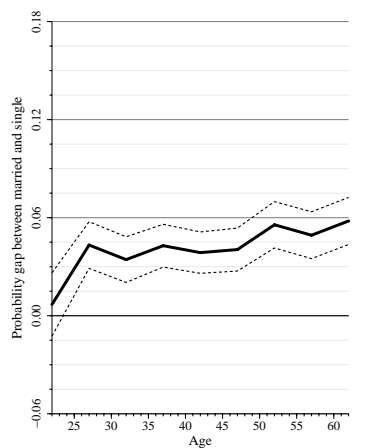

G. Breast examination

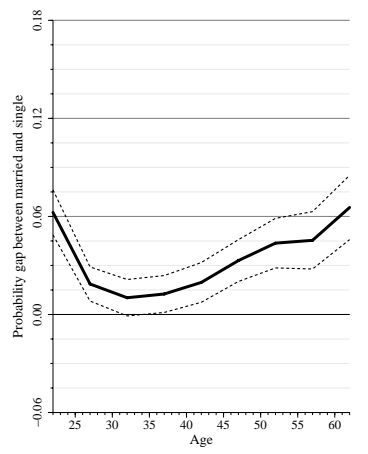

D. Flu shot

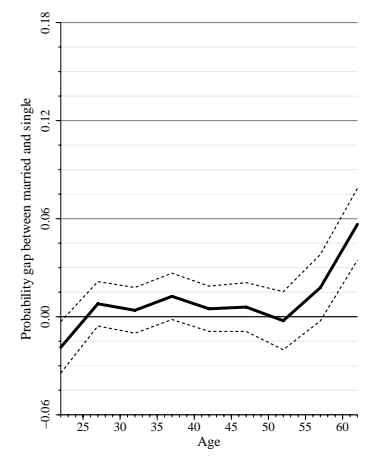

H. Mammography

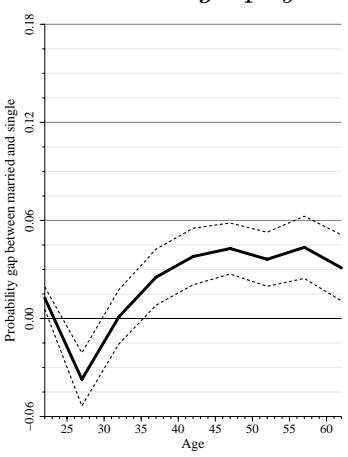

Note: Plotted lines represent OLS estimates of $\beta(a)$ from an equation similar to (1) in which the dependent variable is now an indicator variable that takes the value of one if the individual did the corresponding preventive check. The following preventive checks are considered: dental check at least once every year; cholesterol check, general physical examination, flu shot, prostate examination, Pap smear, breast examination, and mammography at least once in the last two years. The equation is fitted to data from the MEPS. Control variables, $\boldsymbol{x}$, include income, gender (female dummy), race (black dummy), education (college dummy), children (dummies for 0-3, 4-12, and 13-18 year-old children), and survey year (year dummies), as well as current health, health insurance (public and private insurance dummies) and total health expenditures; regressions also estimate $\alpha(a)$. Weights are used in the estimation. The horizontal axis indicates age. In estimation, five-year age bins (20-24, 25-29, 30-34, 35-39, 40-44, 45-49, 50-54, 55-59, and 60-64) are considered. Dotted lines indicate \pm two standard errors confidence bands around point estimates, which are Taylor linearized using survey stratification design in the MEPS. Data construction and variable definitions are described in Appendix A.

older ages, though, unmarried individuals spend more than married ones; at ages 50-59, median expenditure of unmarried individuals is around 100-110\$ larger.

This higher expenditure by married individuals at earlier ages may due to preventive motives, while the higher expenditure by unmarried at older ages may be due to curative motives, as a result of worse health. To further explore this hypothesis, we estimate marriage expenditure gaps for different health statuses. In particular, we extend the median expenditure model to account for heterogeneous curves depending on health, in the spirit of the heterogeneous effects described in equation (2). Panel B of Figure 11 presents median regression estimates of the marriage health expenditure gap for healthy and unhealthy individuals. Married individuals spend slightly more when they are healthy, which is consistent with 
Figure 11. Median Health Expenditures and Marital Status

A. Expenditure gap

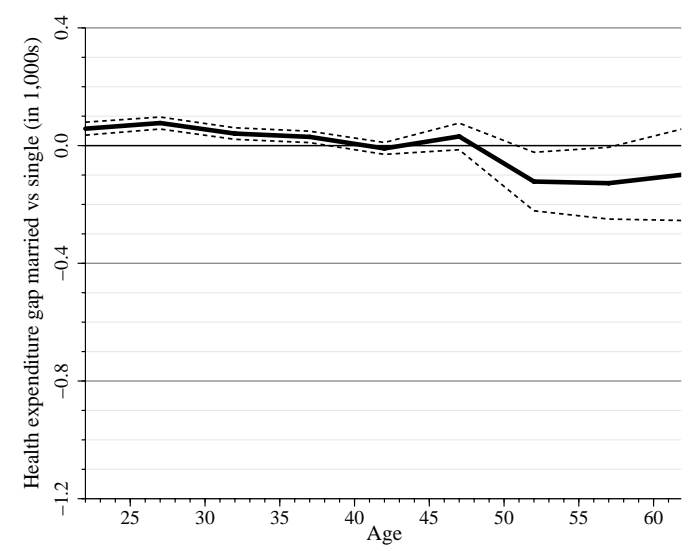

B. Heterogeneous effects by health level

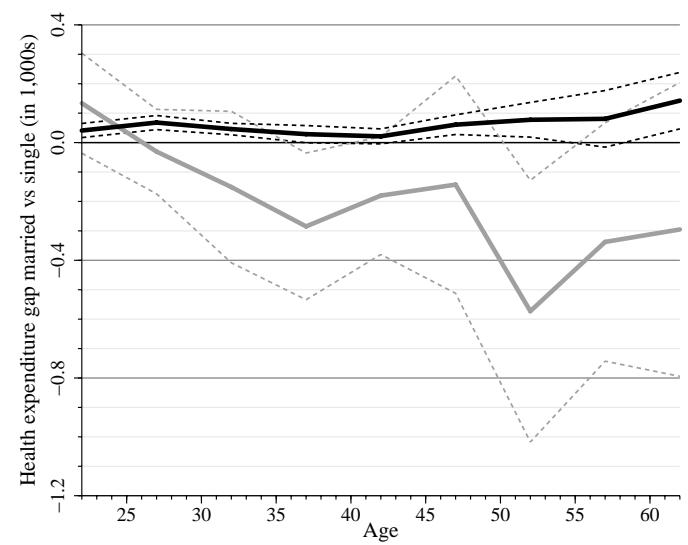

Note: Plotted solid line in Panel A represents median regression estimates of $\beta(a)$ from a model similar to (1), in which total health expenditures is the dependent variable. Plotted solid lines in the Panel B are median regression estimates of $\beta(a, q)$ from an equation similar to (2), where the dependent variable is total health expenditures, and $q_{i t}=h_{i t}$ is an indicator on whether the individual is healthy (black) in that period or not (gray). Control variables, $\boldsymbol{x}$, include income, gender (female dummy), race (black dummy), education (college dummy), children (dummies for 0-3, 4-12, and 13-18 year-old children), and survey year (year dummies), as well as health insurance (public and private insurance dummies); regressions also estimate $\alpha(a)$ and $\alpha(a, q)$ respectively. The equations are fitted to data from the MEPS. The horizontal axis indicates age. In estimation, five-year age bins (20-24, 25-29, 30-34, 35-39, 40-44, 45-49, 50-54, 55-59, and 60-64) are considered. Dotted lines are \pm two standard error bands, obtained by bootstrap with 30 repetitions. Data construction and variable definitions are described in Appendix A.

the fact they they are more likely to do preventive checks. In contrast, unmarried individuals spend substantially more than married ones when they are unhealthy, which suggests that when the unmarried are unhealthy, they are more likely to face serious (and expensive) conditions.

Finally, we check whether entry into marriage is associated with healthy habits. We focus on smoking, a key health factor. In particular, we look at all individuals who were smokers in 1999 and document how many of them quit smoking between 1999 and 2011 conditional on their marital transitions. As Table 5 shows, a single individual is about $13 \%$ points more likely to quit smoking if he/she gets married than if he/she stays single ( $42 \%$ versus $29 \%$ ); additionally, a majority (about $72 \%$ ) of singles who get married and quit smoking do so while they are married. Likewise, a married individual is more likely to quit smoking if he/she stays married than if he/she becomes single (40\% versus $32 \%$ ).

Overall, these results seem to suggest that marriage goes together with healthy behavior. Even after controlling for observables, most importantly income, education and health insurance, preventive health care, measured both by frequency of preventive medical checks and by health expenditure while healthy, is more prevalent among married individuals than it is among singles. Marriage also increases the probability of quitting smoking. 
Table 5-Probability of Quitting Smoking and Marital Transitions

\begin{tabular}{cccc}
\hline \hline \multirow{2}{*}{ Probability of } & \multicolumn{2}{c}{ Probability of quitting smoking... } \\
\cline { 3 - 4 } Single $\rightarrow$ Single & quitting smoking & while married & while single \\
\hline \multirow{2}{*}{ Single $\rightarrow$ Married } & 0.286 & 0.009 & 0.277 \\
& $(0.028)$ & $(0.006)$ & $(0.027)$ \\
Married $\rightarrow$ Single & 0.415 & 0.298 & 0.116 \\
& $(0.052)$ & $(0.048)$ & $(0.033)$ \\
Married $\rightarrow$ Married & 0.318 & 0.052 & 0.266 \\
& $(0.057)$ & $(0.026)$ & $(0.055)$ \\
& 0.395 & 0.389 & 0.006 \\
& $(0.030)$ & $(0.030)$ & $(0.004)$ \\
\hline \hline
\end{tabular}

Note: The table presents the probability that an individual quits smoking between 1999 and 2011 conditional on smoking in 1999, by type of marital status transition. These probabilities are calculated using data from the PSID. Weights are used. In the left column, the numerator is the number of individuals in the corresponding marital transition that were not smoking in 2011 and were smoking in 1999, and the denominator is the number of individuals in the marital transition group that were smoking in 1999. In the right panel, the numerator is changed to include only the individuals that were married/single in the first year we observe them not smoking after their last smoking spell. The total number of observations is 1,007 . Standard errors are in parenthesis.

\section{Health Insurance}

Health insurance status is a key determinant of health care utilization in the U.S. ${ }^{18}$ In the MEPS sample, about $16 \%$ of individuals, who are between 20 and 64 years old, do not have any, public or private, health insurance. Panel A in Figure 12 shows how health insurance status differ by marital status for males and females. For both genders, unmarried individuals are more likely to be uninsured than married ones. The gap is, however, larger for males. At ages 45 to 49, for example, about $10 \%$ of married individuals, male or female, do not have any health insurance. The fraction of uninsured among the unmarried of the same age is less than $20 \%$ for females, while it is higher than $25 \%$ for males. ${ }^{19}$ The larger gap for males reflects the effect of Medicaid that provides health insurance for children and their parents in low-income families. In the MEPS sample, 9.0\% and $17.6 \%$ of unmarried males and females have public health insurance, respectively.

Panel B in Figure 12 documents how medical insurance affect the marriage health gap. We report OLS estimates of equation (2) for individuals with (black line) and without (gray line) health insurance. For individuals with health in-

\footnotetext{
18 See e.g. Anderson, Dobkin and Gross (2012) and Finkelstein, Taubman, Wright, Bernstein, Gruber, Newhouse, Allen, Baicker and the Oregon Health Study Group (2012). Both papers document that changes in health insurance status has a large effect on health care utilization.

19 Bernstein, Cohen, Brett and Bush (2008), using, National Health Interview Survey, report that $13 \%$ of married women between ages 25 and 64 were uninsured in contrast to $21 \%$ of unmarried women of the same age in 2007. For characteristics of uninsured population in the U.S., see Kaiser Family Foundation (2012).
} 
Figure 12. Health Insurance, Health, and Marital Status

A. Fraction uninsured

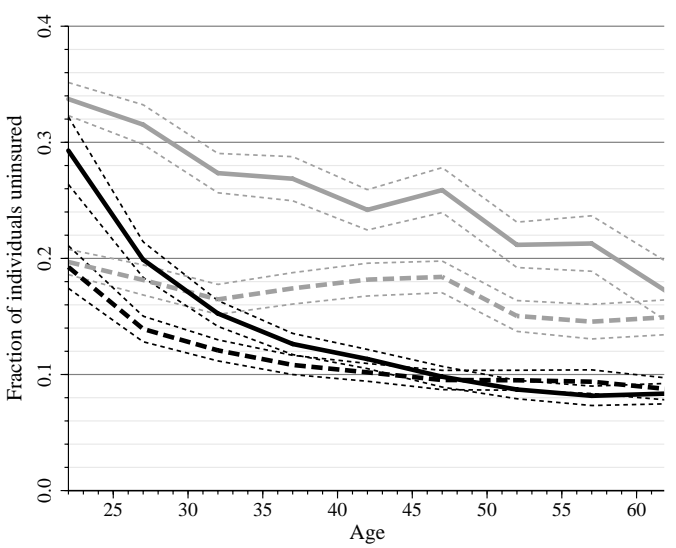

B. Health gap conditional on insurance

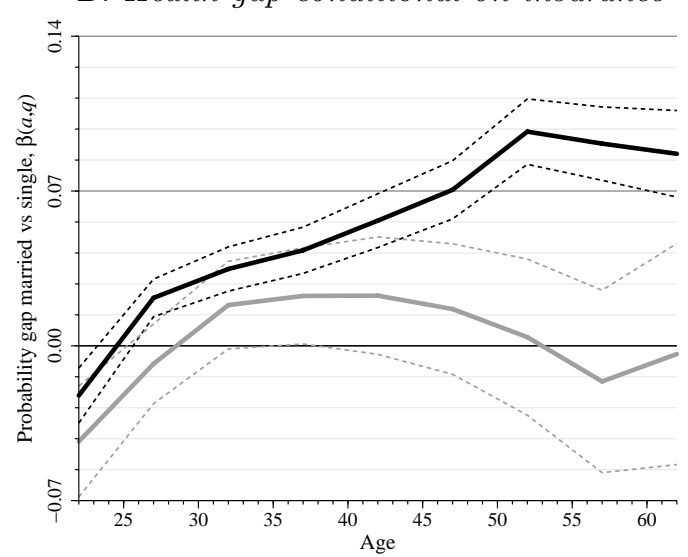

Note: Plotted lines in Panel A represent the weighted fraction of married (black) and unmarried (gray) males (solid) and females (dashed) that are covered by health insurance (public or private). Plotted lines in Panel B are OLS estimates for differential health curves for married individuals compared to single for insured (black) and uninsured (gray), $\beta(a, q)$ from equation (2), where $q$ indicates whether the individual is insured or not. Results are obtained from the MEPS. In the right figure, control variables, $\boldsymbol{x}$, include income, gender (female dummy), race (black dummy), education (college dummy), children (dummies for 0-3, 4-12, and 13-18 year-old children), and survey year (year dummies); regressions also estimate $\alpha(a, q)$. The horizontal axis indicates age. In estimation, five-year age bins (20-24, 25-29, 3034, 35-39, 40-44, 45-49, 50-54, 55-59, and 60-64) are considered. Dotted lines indicate \pm two standard errors confidence bands around point estimates, which are Taylor liniarized computed following the survey stratification design. Data construction and variable definitions are described in Appendix A.

surance, the results are similar to what we document in Figure 4 for the MEPS sample. Married individuals are healthier and the marriage health gap grows by age. For uninsured individuals, however, we do not find any significant marriage health gap. These results suggest that the availability of health insurance is an important facilitator for a positive effect of health on marriage.

\section{Conclusions}

We use data from the Medical Expenditure Panel Survey (MEPS) and the Panel Study of Income Dynamics (PSID) to document differences in health between married and unmarried individuals. After controlling for observables (education, income, race and gender), there exists a marriage health gap of about 12 percentage points in both data sets. We non-parametrically identify health curves for married and single individuals, estimating the marriage health gap as a function of age. Allowing for heterogeneity in innate permanent health, our results suggest that the marriage health gap disappears for younger (20-39) ages, while a positive gap of 6 percentage points remains for older (50-59) ages. We interpret these results as evidence that self-selection into marriage drives the observed marriage health gap at younger ages, while, at older ages, an important fraction of the observed gap is explained by protective effects of marriage on health. 
We provide detailed evidence of self-selection patterns in the data, and on different mechanisms through which marriage exerts a beneficial effect on health. We observe that the distribution of innate permanent health of married individuals is shifted to the right, and less dispersed than that of unmarried individuals. This would be consistent with a marriage search model in which innate health is observable. Such model implies assortative mating in innate health, and that innate health is a good predictor of marriage probabilities, which we find in the data. On the other hand, we document that married individuals are much more likely to engage in preventive care and that the total years of being married (not just current marital status) has a positive effect on health. We interpret these results as indicators of better health production within marriage. We find that health insurance plays an important role in this difference.

\section{REFERENCES}

Adams, Peter, Michael D. Hurd, Daniel McFadden, Angela Merrill, and Tiago Ribeiro, "Healthy, wealthy, and wise? Tests for direct causal paths between health and socioeconomic status," Journal of Econometrics, January 2003, $112(1), 356$.

Aizer, Ayal A., Ming-Hui Chen, Ellen P. McCarthy, Mallika L. Mendu, Sophia Koo, Tyler J. Wilhite, Powell L. Graham, Toni K. Choueiri, Karen E. Hoffman, Neil E. Martin, Jim C. Hu, and Paul L. Nguyen, "Marital Status and Survival in Patients With Cancer," Journal of Clinical Oncology, November 2013, 31 (31), 3869-3876.

Anderson, Michael, Carlos Dobkin, and Tal Gross, "The Effect of Health Insurance Coverage on the Use of Medical Services," American Economic Journal: Economic Policy, February 2012, 4 (1), 1-27.

Arellano, Manuel and Olympia Bover, "Another Look at the Instrumental Variable Estimation of Error-Components Models," Journal of Econometrics, July 1995, 68 (1), 29-51.

- and Stephen Bond, "Some Tests of Specification for Panel Data: Monte Carlo Evidence and an Application to Employment Equations," Review of Economic Studies, April 1991, 58 (2), 277-297.

Bernstein, Amy B., Robin A. Cohen, Kate M. Brett, and Mary Ann Bush, "Marital Status is Associated With Health Insurance Coverage for Working-age Women at all Income Levels, 2007," National Center for Health Statistics Data Brief 11, U.S. Department of Health and Human Services, Cen- 
ter for Disease Control and Prevention December 2008.

Bound, John, "Self-Reported Versus Objective Measures of Health in Retirement Models," Journal of Human Resources, 1991, 26 (1), 106-138.

Buss, David M., The Evolution of Desire: Strategies of Human Mating, New York: Basic Books, 1994.

Chiappori, Pierre-Andre, Sonia Oreffice, and Climent QuintanaDomenque, "Fatter Attraction: Anthropometric and Socioeconomic Matching on the Marriage Market," Journal of Political Economy, August 2012, 120 (4), 659-695.

_, , and _ , "Bidimensional Matching with Heterogeneous Preferences: Smoking in the Marriage Market," IZA Discussion Paper 5392, November 2013.

Clark, Andrew E. and Fabrice Etile, "Don't Give up on Me Baby: Spousal Correlation in Smoking behaviour," Journal of Health Economics., September 2006, 25 (5), 958-978.

Cutler, David M. and Adriana Lleras-Muney, "Understanding Differences in Health Behaviors by Education," Journal of Health Economics, January 2010, $29(1), 1-28$.

Dawkins, Richard, The Selfish Gene, second ed., New York City: Oxford University Press, 1989.

De Nardi, Mariacristina, Eric French, and John Bailey Jones, "Why Do the Elderly Save? The Role of Medical Expenses," Journal of Political Economy, February 2010, 118 (1), 39-75.

Domingue, Benjamin W., Jason Fletcher, Dalton Conley, and Jason D. Boardman, "Genetics and Educational Assortative Mating Among US Adults," Proceedings of the National Academy of Sciences of the United States of America, June 2014, 111 (22), 7996-8000.

Finkelstein, Amy, Sarah Taubman, Bill Wright, Mira Bernstein, Jonathan Gruber, Joseph P. Newhouse, Heidi Allen, Katherine Baicker, and the Oregon Health Study Group, "The Oregon Health Insurance Experiment: Evidence from the First Year," Quarterly Journal of Economics, August 2012, 127 (3), 1057-1106.

French, Eric, "The Effects of Health, Wealth and Wages on Labor Supply and Retirement Behavior," Review of Economic Studies, April 2005, 72 (2), 395427.

Fuchs, Victor R., "The Gross Domestic Product and Health Care Spending," 
The New England Journal of Medicine, July 2013, 369 (2), 107-109.

Gardner, Jonathan and Andrew J. Oswald, "How is mortality affected by money, marriage, and stress?," Journal of Health Economics, November 2004, 23 (6), 1181-1207.

Greenwood, Jeremy, Nezih Guner, Georgi Kocharkov, and Cezar Santos, "Marry Your Like: Assortative Mating and Income Inequality," American Economic Review: Papers and Proceedings, May 2014, 104 (5), 348353.

House, James S., Robert F. Schoeni, George A. Kaplan, and Harold Pollack, "The Health Effects of Social and Economic Policy: The Promise and Challenge for Research and Policy," in James S. House, Robert F. Schoeni, George A. Kaplan, and Harold Pollack, eds., Making Americans Healthier: Social and Economic Policy as Health Policy, Russell Sage Foundation, 2008.

Kaiser Family Foundation, "The Uninsured: A Primer. Key Facts About Americans Without Health Insurance," Technical Report, October 2012.

Kopecky, Karen A. and Tatyana Koreshkova, "The Impact of Medical and Nursing Home Expenses on Savings," American Economic Journal: Macroeconomics, July 2014, 6 (3), 29-72.

Lillard, Lee A. and Constantijn W. A. Panis, "Marital Status and Mortality: The Role of Health," Demography, August 1996, 33 (3), 313-327.

- and Linda J. Waite, "Til Death Do Us Apart: Marital Distruption and Mortality," American Journal of Sociology, March 1995, 100 (5), 1131-1156.

Lleras-Muney, Adriana, "The Relationship Between Education and Adult Mortality in the United States," Review of Economic Studies, January 2005, 72 (1), 189-221.

Murray, John E., "Marital Protection and Marital Selection: Evidence from a Historical-Prospective Sample of American Men," Demography, November 2000, 37 (4), 511-521.

Ozkan, Serdar, "Preventive vs. Curative Medicine: A Macroeconomic Analysis of Health Care over the Life Cycle," mimeo, Federal Reserve Board, July 2013.

Parker-Pope, Tara, "Is Marriage Good for Your Health," The New York Times Magazine, April 142010.

Pijoan-Mas, Josep and José-Víctor Ríos-Rull, "Heterogeneity in Expected Longevities," CEPR Discussion Paper No. 9123, September 2012.

Schoenborn, Charlotte A., "Marital Status and Health: United States, 1999- 
2002," Advance Data from Vital and Health Statistics 351, U.S. Department of Health and Human Services, Center for Disease Control and Prevention December 2004.

Schwartz, Christine R., "Trends and Variation in Assortative Mating: Causes and Consequences," The Annual Review of Sociology, 2013, 39, 45170.

Smith, James P., "The Impact of Socioeconomic Status on Health over the Life-Course," Journal of Human Resources, Fall 2007, XLII (4), 739-764.

Stowasser, Till, Florian Heiss, Daniel McFadden, and Joachim Winter, "Healthy, Wealthy and Wise? Revisited: An Analysis of the Causal Pathways from Socioeconomic Status to Health," in David A. Wise, ed., Investigations in the Economics of Aging, Chicago: University of Chicago Press, 2012.

Waite, Linda J. and Maggie Gallagher, The Case for Marriage: Why Married People are Happier, Healthier and Better Off Financially, New York: Doubleday, 2000.

Williams, Kristi and Debra Umberson, "Marital Status, Marital Transitions, and Health: A Gendered Life Course Perspective," Journal of Health and Social Behavior, March 2004, 45 (1), 81-98.

Wilson, Chris M. and Andrew J. Oswald, "How Does Marriage Affect Physical and Psychological Health? A Survey of the Longitudinal Evidence," IZA Discussion Paper n. 1619, May 2005.

Wood, Robert G., Sarah Avellar, and Brian Goesling, The Effects of Marriage on Health: A Synthesis of Recent Research Evidence, New York: Nova Science Publishers Inc., 2009. 


\section{Appendix A: Data Description and Variable Definitions}

\section{A1. Sample Selection}

Panel Survey of Income Dynamics (PSID) The Panel Study of Income Dynamics (PSID) is administered by the Survey Research Center in the Institute for Social Research at the University of Michigan. The study began in 1968 with a nationally representative sample of over 18,000 individuals living in 5,000 families in the United States. Extensive demographic and economic data on these individuals and their descendants have been collected continuously since then, yearly until 1997 and biannually after that. The PSID started to collect data on health in 1984. We use data from 1984 to 2011 (the latest year of the survey). The analysis is based on the core PSID sample. While the PSID has extensive data on heads and spouses, available data for other household members is limited. Our analysis focuses on heads and spouses based on "sequence number" 1 (head) or 2 (wife).

Medical Expenditure Panel Survey (MEPS) The Medical Expenditure Panel Survey began in 1996 and it is the most complete source of data on the cost and use of health care and health insurance coverage in the United States. The survey has two major components: the Household Component and the Insurance Component. We use the Household Component, which contains extensive information on demographic characteristics, health conditions, health status, usage of medical services, access to care, satisfaction with care, health insurance coverage, income, and employment, at both individual and household levels, supplemented by information from their medical providers. The survey has a rotating panel structure in which each individual is interviewed 5 times during a 2-year period and then replaced. The sample includes about 31,000 individuals per year, with some variance across years, and it is representative of the U.S. population. As we do not exploit the short panel dimension of the data set, for each year we consider the cross-section of available individuals. Some of the variables are only available at a yearly basis. Others are available at each of the five interviews over the two-year period. In the latter case, for each individual, we consider his/her first interview of the year. We use survey years 1996 to 2009.

Both in the PSID and in the MEPS, we clean our samples by dropping observations that have no compete information on self-reported health, marital status, gender, race, or income. We focus on working-age individuals, so we consider individuals aged 20 to 64 . 


\section{A2. Variable Definitions}

Self-Reported Health Our main health variable is constructed from the reported self-rated health. Individuals rate their health as "excellent", "very good", "good", "fair" or "poor". We create a health dummy where 1 (healthy) corresponds to the first three grades, and 0 (unhealthy) to the other two.

Marital Status Marital status is defined as one of four possible status as reported by individuals: "married", "divorced/separated", "widowed", "separated" and "never married". In the PSID, if a respondent reported to be widowed, divorced or separated in a previous period, but reports to be never married in current one, he/she is assigned his/her previously-reported marital status. The MEPS contains two questions on marital status: "what is your current marital status?" and "what was your marital status in previous round" (which means after the previous interview, but before the current one). Whenever available, marital status is determined based on the first question; the second question is used otherwise.

Age We create five-year age bins: 20-24, 25-29, 30-34, etc.

Gender Gender is self-reported.

Race Based on self-reported race, we create a "black" dummy, which we use as a control in most of the regressions. Additionally, we also create a "white" dummy that is used when we compute heterogeneous health gaps by race (Figures 2 and 8).

Education Our main education variable is a dummy that takes the value of one if the individual received a college degree, based on the responses to "did you receive a college degree?" or "did your wife receive a college degree?" in the PSID or "highest degree attained" in the MEPS (in which case, college degree is defined as bachelor's degree or more). In the PSID, if a person reported that he/she has a college degree in a previous year, but the answer to this question is missing in a later year, we use previous answer to fill the missing observation. In the last column of Table 4, we use the number of years of education of the individual to compute our measure of permanent income. This information is based on the response to the question "what is the highest grade or year of school that you have completed?". For that particular exercise, observations with DK/NA codes are dropped. Whenever possible, missing or zero observations are imputed from valid answers to this questions from preceding or following interviews. If a respondent reports a lower completed grade in an interview after he/she reports a higher one in a previous interview, we consider the higher value. 
Children Presence of children in the household is identified from the question "children under 18 in the family unit". From the record of each child in the household, we identify their age and create dummy variables for the presence of children of the ages 0 to 3,4 to 12 , and 13 to 18 .

Income Our definition of income is "taxable income" in the PSID or "total person's income" in the MEPS. For couples (married or cohabiting), we calculate household taxable income by summing the total taxable incomes of the head and the spouse and then divide the total taxable income by 2 . This variable is deflated using 2005 Consumer Price Index (CPI), obtained from the Bureau of Labor Statistics.

Marital capital (PSID) Marital capital is defined as the sum of the durations of all (past and present) marriages. Duration of a given marriage is calculated as the difference between either the year of divorce/separation/widowhood or the current year (depending on whether the marriage ended or is ongoing), and the starting year of the marriage. This information is obtained from the Marriage History Supplement of the PSID.

Chronic conditions (PSID) We consider the following chronic conditions: stroke, hypertension, diabetes, cancer, lung disease, heart attack, heart disease, arthritis, asthma, memory loss, and learning disorder. For each of them, we create a dummy that equals one if you ever suffered that condition. Our chronic conditions variable is defined as the sum of these dummies across all conditions. Hence, it measures the number of different conditions the individual ever suffered.

Smoking (PSID) An individual is classified as a smoker if he answered the question "do you smoke cigarettes?" affirmatively or the household head did so for the question "does your wife smoke cigarettes?". Smoking transitions conditional on marital transitions are then computed as described in the main text.

Cohabitation (PSID) Cohabitants are identified from the variable "relationship to head". This variable takes the following values: 10 (head), 20 (legal wife), 90 (legal husband of head, if in rare cases the head is a female), 22 (female cohabitant who has lived with the head for 12 months or more), 88 (first-year cohabitant, boyfriend or girlfriend, of head). To identify cohabitants we use codes 22 and 88 .

Objective Health Index (MEPS) We use the Physical Summary Component of the Short Form 12 version 2 (SF-12v2) as an objective index of health. In 2000, 2001, and 2002, MEPS used Version 1 of the SF-12. Therefore for these years, Version 1 scores are converted to Version 2 scores by adding 1.07897. 
Further details are available at http://meps.ahrq.gov/data_stats/download_ data/pufs/h147/h147doc.pdf.

Preventive checks (MEPS) For each preventive check (dental, cholesterol, general, flu shot, prostate check, pap smear, breast examination and mammography), we create a dummy variable that is equal to 1 if a person did the corresponding check within the preceding two years and zero otherwise.

Medical expenditure (MEPS) We use total medical (health care) expenditures. Expenditures are defined as the sum of direct payments for care provided during the year, including out-of-pocket payments and payments by private insurance, Medicaid, Medicare, and other sources. Payments for over the counter drugs and for alternative care services are not. Indirect payments not related to specific medical events, such as Medicaid Disproportionate Share and Medicare Direct Medical Education subsidies, are also not included either. Whenever medical expenditure is used, we drop observations with unavailable medical expenditure. Expenditures are deflated by 2005 medical CPI, available at http://data.bls.gov/cgi-bin/surveymost?cu.

Insurance (MEPS) We use the insurance coverage variable and distinguish between "any private insurance", "any public insurance" and "no insurance". Whenever indicated, we create two dummies, public or private, which take the value of one if the individual holds the corresponding insurance (public and private insurance are not mutually exclusive). Otherwise, we create an indicator variable that equals one if the individual holds any insurance, public or private. Whenever insurance information is used, observations with unavailable insurance are dropped. 


\section{Appendix B: Descriptive Statistics and Detailed Baseline Results}

TABle B1-Descriptive Statistics

\begin{tabular}{|c|c|c|c|c|c|}
\hline \multicolumn{6}{|c|}{ A. Panel Study of Income Dynamics (PSID) } \\
\hline & Mean & St. dev. & Min & Max & N.obs. \\
\hline \multicolumn{6}{|l|}{ i. Baseline } \\
\hline Healthy & 0.89 & 0.31 & 0.00 & 1.00 & 120,475 \\
\hline Married & 0.65 & 0.48 & 0.00 & 1.00 & 120,475 \\
\hline Divorced/separated & 0.15 & 0.36 & 0.00 & 1.00 & 120,475 \\
\hline Widowed & 0.01 & 0.12 & 0.00 & 1.00 & 120,475 \\
\hline Never Married & 0.19 & 0.39 & 0.00 & 1.00 & 120,475 \\
\hline Age & 39.78 & 11.49 & 20.00 & 64.00 & 120,475 \\
\hline Female & 0.45 & 0.50 & 0.00 & 1.00 & 120,475 \\
\hline Black & 0.12 & 0.33 & 0.00 & 1.00 & 120,475 \\
\hline College & 0.38 & 0.49 & 0.00 & 1.00 & 120,475 \\
\hline Children 0-3 years & 0.18 & 0.39 & 0.00 & 1.00 & 120,475 \\
\hline Children $4-12$ years & 0.31 & 0.46 & 0.00 & 1.00 & 120,475 \\
\hline Children $13-18$ years & 0.21 & 0.41 & 0.00 & 1.00 & 120,475 \\
\hline Taxable income (in $1000 \$$ ) & 37.86 & 51.00 & -590.38 & 5500.00 & 120,475 \\
\hline \multicolumn{6}{|c|}{ ii. Robustness and further explorations } \\
\hline Chronic conditions & 0.65 & 1.02 & 0.00 & 10.00 & 44,022 \\
\hline Married+cohabiting & 0.72 & 0.45 & 0.00 & 1.00 & 120,475 \\
\hline Smoke & 0.23 & 0.42 & 0.00 & 1.00 & 49,241 \\
\hline
\end{tabular}

\begin{tabular}{|c|c|c|c|c|c|}
\hline \multirow{2}{*}{\multicolumn{5}{|c|}{ B. Medical Expenditure Panel Survey (MEPS) }} & \\
\hline & & & & & \\
\hline & Mean & St. dev. & Min & $\operatorname{Max}$ & N.obs. \\
\hline \multicolumn{6}{|l|}{ i. Baseline } \\
\hline Healthy & 0.88 & 0.31 & 0.00 & 1.00 & 235,094 \\
\hline Married & 0.58 & 0.47 & 0.00 & 1.00 & 235,094 \\
\hline Divorced/separated & 0.14 & 0.33 & 0.00 & 1.00 & 235,094 \\
\hline Widowed & 0.02 & 0.13 & 0.00 & 1.00 & 235,094 \\
\hline Never Married & 0.26 & 0.42 & 0.00 & 1.00 & 235,094 \\
\hline Age & 40.66 & 11.70 & 20.00 & 64.00 & 235,094 \\
\hline Female & 0.51 & 0.48 & 0.00 & 1.00 & 235,094 \\
\hline Black & 0.12 & 0.31 & 0.00 & 1.00 & 235,094 \\
\hline College & 0.35 & 0.46 & 0.00 & 1.00 & 235,094 \\
\hline Children $0-3$ years & 0.15 & 0.34 & 0.00 & 1.00 & 235,094 \\
\hline Children $4-12$ years & 0.26 & 0.42 & 0.00 & 1.00 & 235,094 \\
\hline Children $13-18$ years & 0.38 & 0.46 & 0.00 & 1.00 & 235,094 \\
\hline Taxable income (in $1000 \$$ ) & 34.61 & 30.70 & 0.00 & 658.58 & 235,094 \\
\hline \multicolumn{6}{|c|}{ ii. Robustness and further explorations } \\
\hline Objective health index & 51.15 & 9.26 & 4.56 & 76.13 & 160,057 \\
\hline Total health expenditure & 3.04 & 9.47 & 0.00 & 1051.50 & 235,094 \\
\hline Uninsured & 0.16 & 0.35 & 0.00 & 1.00 & 235,094 \\
\hline \multicolumn{6}{|l|}{ Preventive checks: } \\
\hline Dental & 0.50 & 0.48 & 0.00 & 1.00 & 231,873 \\
\hline Cholesterol & 0.51 & 0.48 & 0.00 & 1.00 & 221,942 \\
\hline Complete & 0.57 & 0.47 & 0.00 & 1.00 & 227,623 \\
\hline Flu shot & 0.26 & 0.42 & 0.00 & 1.00 & 229,296 \\
\hline Prostate & 0.22 & 0.38 & 0.00 & 1.00 & 90,412 \\
\hline Pap smear & 0.54 & 0.48 & 0.00 & 1.00 & 140,965 \\
\hline Breast & 0.55 & 0.48 & 0.00 & 1.00 & 136,720 \\
\hline Mammography & 0.36 & 0.46 & 0.00 & 1.00 & 119,403 \\
\hline
\end{tabular}

Note: Means and standard deviations are computed exploiting sampling design. Data are obtained from the PSID and the MEPS as indicated. PSID sample covers 1984-2011, annually until 1997, biannually since then; MEPS sample covers 1996-2009 annually. Chronic conditions and smoking are only available in the PSID starting in 1999. Data construction and variable definitions are described in Appendix A. 
Table B2-Detailed Estimation Results for Figures 4 And 5

\begin{tabular}{|c|c|c|c|c|c|c|}
\hline & \multirow{2}{*}{\multicolumn{2}{|c|}{$\frac{\text { MEPS }}{\mathrm{OLS}}$}} & \multicolumn{4}{|c|}{ PSID } \\
\hline & & & \multicolumn{2}{|c|}{ OLS } & \multicolumn{2}{|c|}{ Within-groups } \\
\hline \multicolumn{3}{|l|}{ Marriage gap $\beta(a)$ : } & & & & \\
\hline $20-24$ & -0.027 & $(0.006)$ & 0.009 & $(0.007)$ & -0.010 & $(0.007)$ \\
\hline $25-29$ & 0.014 & $(0.004)$ & 0.024 & $(0.006)$ & -0.006 & $(0.005)$ \\
\hline $30-34$ & 0.030 & $(0.004)$ & 0.027 & $(0.006)$ & -0.001 & $(0.006)$ \\
\hline $35-39$ & 0.039 & $(0.005)$ & 0.043 & $(0.009)$ & -0.001 & $(0.007)$ \\
\hline $40-44$ & 0.051 & $(0.006)$ & 0.054 & $(0.011)$ & 0.010 & $(0.008)$ \\
\hline $45-49$ & 0.063 & $(0.006)$ & 0.071 & $(0.013)$ & 0.023 & $(0.010)$ \\
\hline $50-54$ & 0.085 & $(0.007)$ & 0.083 & $(0.015)$ & 0.048 & $(0.012)$ \\
\hline $55-59$ & 0.078 & $(0.008)$ & 0.120 & $(0.020)$ & 0.054 & $(0.017)$ \\
\hline $60-64$ & 0.078 & $(0.009)$ & 0.107 & $(0.022)$ & 0.037 & $(0.017)$ \\
\hline \multicolumn{7}{|l|}{ Singles health curve $\alpha(a)$ : } \\
\hline $20-24$ & 0.917 & $(0.004)$ & 0.922 & $(0.007)$ & 0.028 & $(0.026)$ \\
\hline $25-29$ & 0.873 & $(0.004)$ & 0.898 & $(0.007)$ & 0.037 & $(0.024)$ \\
\hline $30-34$ & 0.835 & $(0.005)$ & 0.877 & $(0.009)$ & 0.041 & $(0.023)$ \\
\hline $35-39$ & 0.807 & $(0.006)$ & 0.845 & $(0.011)$ & 0.045 & $(0.021)$ \\
\hline $40-44$ & 0.778 & $(0.006)$ & 0.811 & $(0.012)$ & 0.036 & $(0.020)$ \\
\hline $45-49$ & 0.741 & $(0.006)$ & 0.768 & $(0.014)$ & 0.021 & $(0.019)$ \\
\hline $50-54$ & 0.704 & $(0.007)$ & 0.724 & $(0.015)$ & -0.001 & $(0.017)$ \\
\hline $55-59$ & 0.691 & $(0.007)$ & 0.662 & $(0.020)$ & -0.012 & $(0.016)$ \\
\hline $60-64$ & 0.682 & $(0.009)$ & 0.646 & $(0.021)$ & & \\
\hline \multicolumn{7}{|l|}{ Controls: } \\
\hline College & 0.055 & $(0.002)$ & 0.073 & $(0.006)$ & 0.009 & $(0.009)$ \\
\hline Female & 0.000 & $(0.002)$ & -0.005 & $(0.005)$ & & \\
\hline Black & -0.020 & $(0.003)$ & -0.069 & $(0.010)$ & & \\
\hline Children $0-3$ years & 0.001 & $(0.000)$ & 0.001 & $(0.000)$ & 0.000 & $(0.000)$ \\
\hline Children 4-12 years & 0.001 & $(0.002)$ & -0.004 & $(0.003)$ & 0.003 & $(0.003)$ \\
\hline Children $13-18$ years & 0.001 & $(0.003)$ & 0.000 & $(0.004)$ & 0.006 & $(0.003)$ \\
\hline Taxable income (in $1000 \$$ ) & 0.001 & $(0.003)$ & -0.013 & $(0.004)$ & 0.006 & $(0.003)$ \\
\hline Year dummies: & \multicolumn{2}{|c|}{ Yes } & \multicolumn{2}{|c|}{ Yes } & \multicolumn{2}{|c|}{ Yes } \\
\hline
\end{tabular}

Note: The table reports point estimates and standard errors from regressions presented in Figures 4 and 5. OLS and Within-groups estimates are obtained from the PSID and the MEPS as indicated. 


\section{Appendix C: Additional Results}

Figure C1. Health and Marital Status, Different Socioeconomic Groups (MEPS)

A. Male vs female

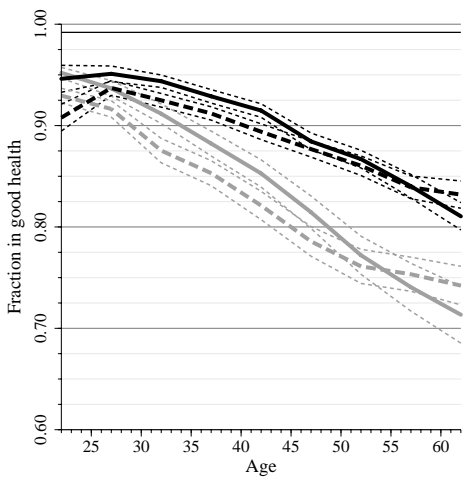

D. College vs non-College

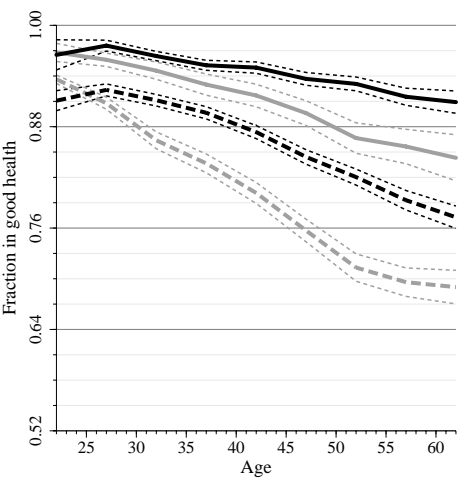

B. White vs black

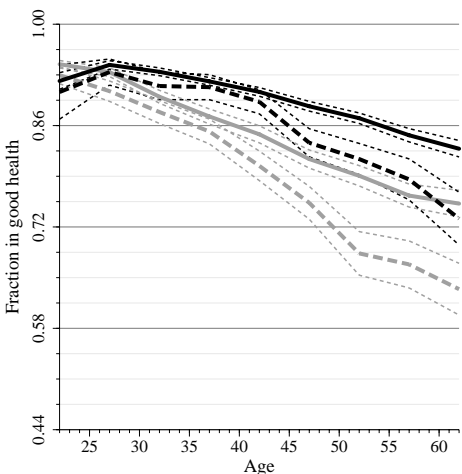

C. Without vs with children (0-12)

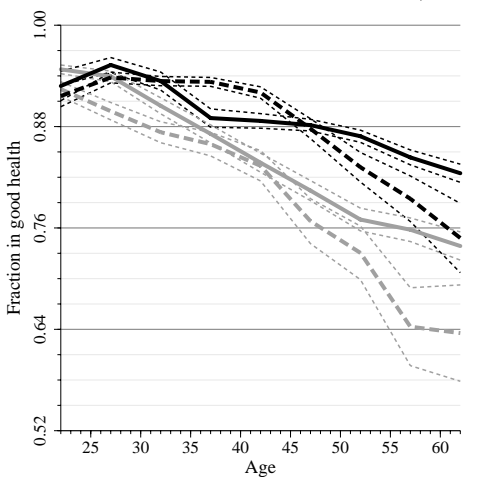

E. Above vs below median income

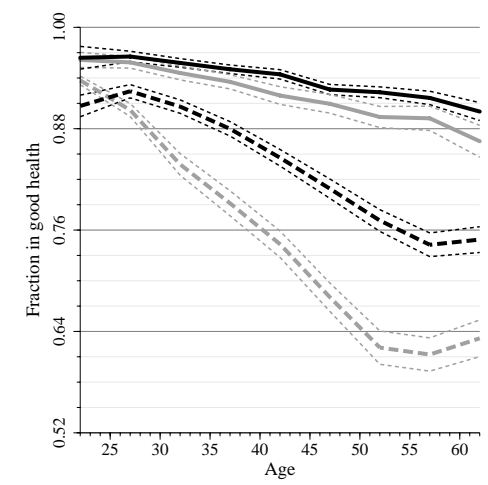

Note: Plotted lines represent the weighted fraction of married (black) and unmarried (gray) individuals that report being healthy, obtained from the MEPS. Fractions are reported for: A. male (solid) and female (dashed), B. white (solid) and black (dashed), C. without (solid) and with (dashed) children aged 0-12 living in the household, D. college graduates (solid) and non-college (dashed), and E. above (solid) and below (dashed) median income. The horizontal axis indicates age, which is grouped in fiveyear categories (20-24, 25-29, 30-34, 35-39, 40-44, 45-49, 50-54, 55-59, and 60-64). Dotted lines around point estimates indicate confidence bands of \pm two standard errors, which are computed using sample stratification design. Data construction and variable definitions are described in the Appendix A. 